\title{
Research Paper \\ Predicting sexual variety based on sensation seeking by mediating cognitive schemas activated among married men referring to counseling centers: a study on the structural equation model
}

\begin{abstract}
Citation: Tabatabaee Shoorijeh M, Deyreh E, Keykhosravani M, Pooladi Rishehri A. Predicting sexual variety based on sensation seeking by mediating cognitive schemas activated among married men referring to counseling centers: a study on the structural equation model. J of Psychological Science. 2021; 20(105): 1667-1682.
\end{abstract}

Mehrdad Tabatabaee Shoorijeh ${ }^{1}$, Ezat Deyreh ${ }^{2}$, Moloud Keykhosravani ${ }^{2}$, Ali Pooladi Rishehri ${ }^{3}$

1. Ph.D Student of Psychology, Bushehr Branch, Islamic Azad University, Bushehr, Iran.

2. Assistant Professor of Psychology Department,Bushehr Branch, Islamic Azad University, Bushehr, Iran.

3. Assistant Professor of Psychology Department, Payame Noor University of Boushehr Branch, Iran.
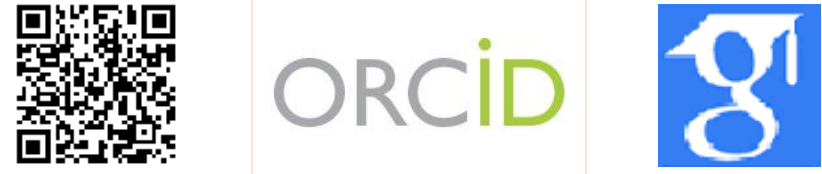

URL: https://psychologicalscience.ir/article-1-1000-fa.html

\section{$\underline{10.52547 / J P S .20 .105 .1667}$}

\section{A R T I C L E I N F O}

Keywords:

sexual variety,

Sensation seeking, cognitive activated

schemas

Received: 20 Oct 2020

Accepted: 07 Nov 2020

Available: 22 Nov 2021

\section{A B S T R A C T}

Background: Numerous studies have examined the relationship between sexual variety, activated cognitive schemas and sensation seeking among men. However, research on the development of a structural model for predicting sexual variety based on sensation seeking by mediating cognitive schemas activated among married men has been neglected.

Aims: The present study aimed to investigate the structural equation model for predicting sexual variety based on sensation seeking by mediating cognitive schemas activated among married men in Shiraz.

Methods: The research method was descriptive-correlational based on structural equation modeling. The statistical population consisted of all married men referring to counseling centers in Shiraz. Of this number, 240 men were selected by using availability sampling method. For collecting data, sexual variety Questionnaire (Glass \& Wright, 1992), Sensation seeking scale (Arnett, 1994), and Cognitive Schema Activation in Sexual Context Questionnaire (Nobre \& Pinto-Gouveia, 2009) were used.The fitness of the proposed model was estimated through structural equation modeling.

Results: The results of the research showed that the research model has a good fit. The results of Pearson 's correlation coefficient test showed that there is a significant relationship between sensation seeking variables, cognitive activated schemas and sexual variety $(\mathrm{P}<0.001)$. The results of path analysis showed that sensation seeking has a direct and indirect effect on cognitive schemas activated in sexual context and sexual variety $(\mathrm{P}<0.001)$. The results of regression analysis showed that activated schemas in sexual context have significant effects on sexual variety in married men $(\mathrm{P}<0.001)$.

Conclusion: Therefore, it can be concluded that sensation seeking has a direct and indirect significant effect on sexual variety in married men. Activated schemas had a mediating role between sensation seeking components and sexual variety.

* Corresponding Author: Ezat Deyreh, Assistant Professor of Psychology Department, Bushehr Branch, Islamic Azad University, Bushehr, Iran.

E-mail: Ezatdeyreh@iaubushehr.ac.ir

Tel: (+98) 9177736156

2476-5740/ (C) 2021 The Authors. This is an open access article under the CC BY-NC-ND license

(https://creativecommons.org/licenses/by-nc/4.0/). 


\section{Extended Abstract}

\section{Introduction}

One of the factors that endanger the continuation of family life is infidelity in marriage, which is often accompanied by a kind of secrecy (Navaei \& Mohammadi Arya, 2016), and any kind of secrecy from the spouse in establishing extramarital affairs is usually is rooted in sexual variety (Frederick, Lever, Gillespie \& Garcia, 2017). Sexual variety is a violation of the commitment of a two-person relationship that leads to the formation of some degree of emotional and physical intimacy with someone outside the relationship (Medina, 2013). According to some researchers, emotional experiences resulting from sexual intercourse with someone other than the spouse (Selterman, Garcia \& Tsapelas, 2019) and emotional intimacy with another person (John, Seme, Roro \& Tsui, 2017) are the source of sexual variety.

One of the factors of sexual variety is sensation seeking (Efrati, Shukron \& Epstein, 2019). Sensation seeking is a personality trait that is defined as the need to gain new and different experiences and feelings (Ziyarati Kord, 2020) and is a good predictor for sexual behaviors, frequency of relationships, and sexual interests (Alipour, Saeidpour \& Hasani, 2015). Sensation seeking reflects a person's desire to pursue intensity and freshness in emotional experience (Paat, Torres, Morales, Srinivasan \& Sanchez, 2020). The Relationship between Sensation seeking and Sexual Variety is rooted in sexual extravagance (Selterman, Garcia \& Tsapelas, 2019), sexual pleasure (Gomes \& Nobre, 2012), and sexual pleasure (Wood, Hirst, Wilson \& Burns-O'Connell, 2019).Since after marriage, sensation seekers may not be easily drawn to free sex, it is possible that other variables between the two variables of sexual variety and sensation seeking play a mediating role (Peixoto \& Nobre, 2015). One of the variables that according to the study of Peixoto \& Nobre (2020) can play a mediating role in extramarital relationships and cognitive and emotional variables, is cognitive schemas activated in sexual context. These cognitive structures influence the course of a marital relationship. These beliefs activate negative cognitive schemas. Activated cognitive schemas are specific cognitive-emotional mechanisms that are responsible for activating and directing emotional and sexual responses. Nobre \& Pinto-Gouveia (2009) first proposed activated cognitive schemas in four main areas: incompetence, loneliness, depreciation, and rejection. When a person experiences an unsuccessful sexual situation with his spouse, these schemas are activated and prevent him from focusing on satisfying sexual intercourse with his spouse. Loneliness schema is due to marital intimacy (Peixoto \& Nobre, 2017), incompetence schema is due to incompetence in marital relations with the spouse and inability to meet the expectations of the spouse (Peixoto \& Nobre, 2020), rejection schema is due to lack of attractiveness and boredom in marital relations (Efrati, Shukron \& Epstein, 2019), and depreciation scheme is due to the feeling of worthlessness in emotional and sexual relationships with the spouse (Ziyayi, Sepehri Shamlou \& Mashhadi, 2013).

Due to dissatisfaction with sexual and emotional needs, negative schemas activated provide the basis for marital problems and extramarital affairs (Efrati, Shukron \& Epstein, 2019).According to Efrati, Shukron and Epstein (2019) novelty of sexual experiences and physical attractiveness have the most irrational effect on the sensation-seekers schemas. They found that men with sexual problems, such as heterosexual variety or homosexuality, scored higher on incompetency and rejection schemas than healthy men.

The causes of sexual variety in all societies, especially in Iran, have remained largely unknown due to moral and cultural conditions (Sharifian, M., Saffarinia, M., \& Alizadehfard, 2018). Identifying the factors affecting sexual variety has a great role in preventing family breakup and divorce. In particular, considering that sexual variety jeopardizes marital commitment and prepares the ground for marital relationship deterioration (Alaghband, Sharifi, Farzad $\&$ Aghayousefi, 2020). Therefore, it is necessary to identify the underlying causes of sexual variety and to discover the direct and indirect relationships that these causes can have. Given what has been mentioned, the main question of the present study is to answer the question that whether the proposed 


\section{Monthly Journal of Psychological Science}

model of sensation seeking mediated by cognitive schemas activated in predicting sexual variety of married men referring to counseling centers in Shiraz has a good fit?

\section{Method}

The research method was a descriptive-correlational based on structural equation modeling. The present study population was all married men who had been married for at least four years and due to marital infidelity and sexual problems, had referred to counseling centers in Shiraz from February 2019 to May 2019, their number was 439. Among the counseling centers in Shiraz, 6 centers were willing to cooperate with this research. The sample group was selected by available method and according to the satisfaction of individuals to participate in the research. According to Kline (2011), the sample size for each variable was approximately 15 to 20 times the subscales of research tools, so 225 men were estimated. To be sure, 240 men from the entire statistical population were selected. The collection tools in this study were a 17-item sexual variety
Vol. 20, No. 105, Autumn(December) 2021

questionnaire made by Glass and Wright (1992) with Cronbach's alpha of 0.91.Also, the cognitive schema activation questionnaire in sexual context made by Nobre \& Pinto-Gouveia (2009) was used. This questionnaire had 28 items with a reliability coefficient of 0.97. Arnett's (1994) 20-item sensation seeking scale was used to measure the excitability variable. Arnett (1994) reported its internal reliability coefficient in the range of 0.83 to 0.86 . The Structural equation modeling was performed using SPSS software version 22 and Amos version 22.

\section{Results}

To determine the relationship between the variables, the correlation coefficient between the studied variables was calculated, the results of which are shown in table 1.As can be seen, there is a significant relationship between sexual variety, sensation seeking, and activated cognitive schemas. The final structural equation model for predicting sexual variety based on emotion seeking and mediated by activated cognitive schemas in married men is presented in figure 1.

Table 1. The relationship between sensation seeking and cognitive schemas activated with Sexual variety

\begin{tabular}{cccccc}
\hline Variables & Incompetence & Rejection & Loneliness & Depreciation & Variety \\
\hline Intensity & $0.289^{* *}$ & $0.573^{* *}$ & $0.278^{* *}$ & $0.639^{* *}$ & $0.533^{* *}$ \\
Novelty & $0.416^{* *}$ & $0.461^{* *}$ & $0.291^{* *}$ & $0.392^{* *}$ & $0.420^{* *}$ \\
Sensation Seeking (Total) & $0.453^{* *}$ & $0.424 * *$ & $0.238^{* *}$ & $0.554^{* *}$ & $0.332^{* *}$ \\
Sexual variety & $0.263^{* *}$ & $0.381^{* *}$ & $0.392^{* *}$ & $0.370^{* *}$ & 1 \\
\hline$* * \mathrm{P}<0.001$ & & & &
\end{tabular}

$* * \mathrm{P}<0.001$

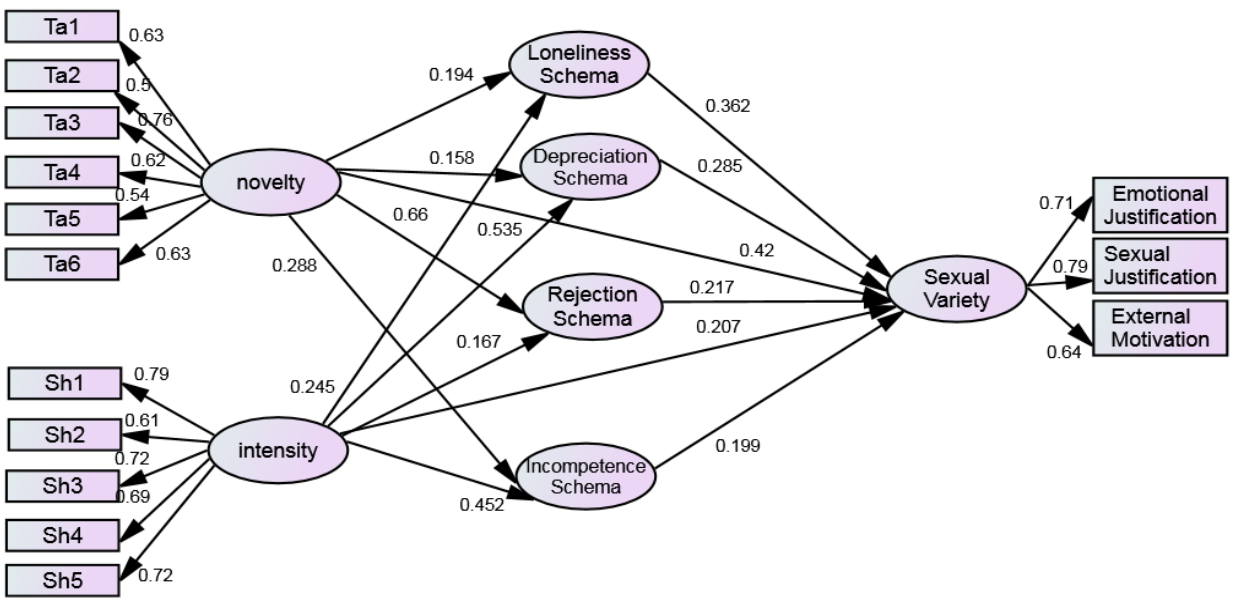

Figure 1: The final research model 


\section{Conclusion}

The present study aimed to investigate the structural equation model for predicting sexual variety based on sensation seeking by mediating cognitive schemas activated among married men in Shiraz. The results showed that the proposed model of this research has a good fit. Thus, it can be said that sexual variety can be predicted based on sensation seeking and the mediation of cognitive schemas activated. Explaining this finding, it can be said that Sensation seeking has a significant direct and indirect effect through the mediation of cognitive schemas activated on sexual variety, which can indicate the stressful effect of unmet desires and unmet emotional needs. The reexperience of emotional and sexual intimacy, something they no longer find in their cohabitation, the attraction that illegitimate relationships have for them, and the fact that neither party seeks fault, blame, or boast, justifies the sexual variety of this group of individuals (Selterman, Garcia \& Tsapelas, 2019). Importantly, most people referring to counseling centers to solve marital problems are frustrated with modifying their core behavioral patterns and insist that these underlying beliefs (schemas) and behaviors are an integral part of their existence, and therefore they cannot change them. For this reason, they are looking for a way to reduce psychological stress, change their marital life with their spouse. Sensation seeking and dissatisfaction with emotional needs stimulate cognitive schemas that activate and even intensify marital dissatisfaction of men with sexual variety.
Also, the results of the present study showed that the components of sensation seeking, including the intensity and novelty, have a direct effect on sexual variety and activated schemas (loneliness, depreciation, rejection, and incompetence), and this effect is transmitted by schemas on sexual variety. The beta coefficient showed that the effect of sensation seeking increases with the entrance of activated schemas. In explaining this finding, we can say; if the relationship with the sexual partner is satisfactory, the emotional needs are satisfied and a positive perception of marital quality is strengthened. As a result, the marital relationship does not deviate from the original path. Otherwise, these activated cognitive schemas lead the person to leave the existing marital relationship. In this way, certain cognitive and emotional variables, such as cognitive schemas activated, mediate the connection between sensation seeking and sexual variety.

\section{Ethical Considerations}

Compliance with ethical guidelines: In conducting the research, in addition to not writing the names of individuals on the research questionnaires, the subjects were assured that their information would be kept confidential in order to comply with ethical standards. Also, the subjects' free will to leave the research was observed in order to maintain human dignity.

Funding: This study was conducted as a $\mathrm{PhD}$ thesis with no financial support.

Authors' contribution: The first author was the senior author, the second was the corresponding author and first supervisors, the third was the second supervisor, and the forth was the advisor.

Conflict of interest: The authors declare no conflict of interest for this study.

Acknowledgments: I would like to thank the supervisors, the advisor, and all the participants in this study. 


\section{ييش بينى تنوع طلبى جنسى بر اساس هيجانخ ئواهى با ميانجى كرى طرحوارههاى شناختى فعالشونده در مردان مر اجعه كننده به مراكز مشاوره: بروسى مدل ميد معادلات ساختى}

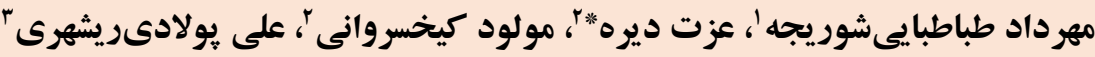

1. دانشجوى دكترى روانشناسى، واحد بوشهر، دانشكاه آزاد اسلامى، بوشهر، ايران.

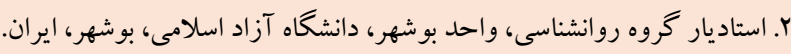

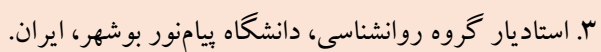

جكيu"

زمينه: مطالعات متعددى به بررسى رابطه هيجانخواهى، طرحوارههاى شناختى فعالشونده و تنوعطلبى جنسى در مردان برداختهاند. اما

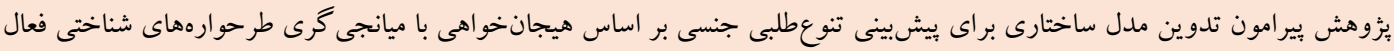
شونده در مردان متأهل، مورد غفلت واقع شده است.

هدف: يزوهش حاضر، با هدف بررسى مدل معادلات ساختارى ييشبينى تنوع طلبى جنسى بر اساس هيجانخو اهى با ميانجى گرى طر حواره

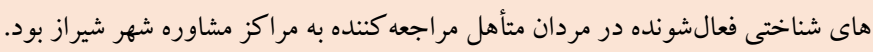

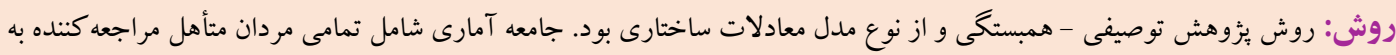

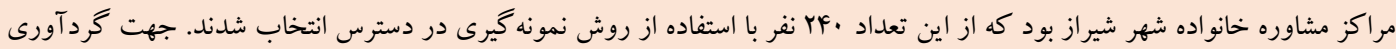

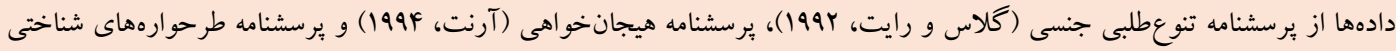

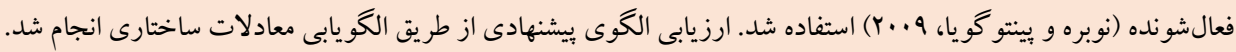

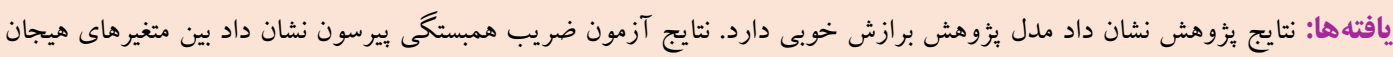

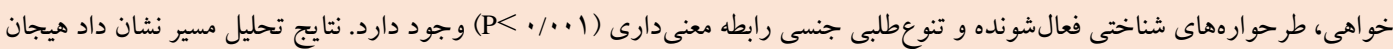

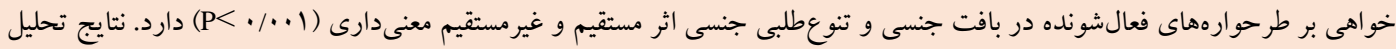

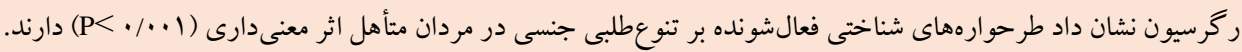
نتيجه كيرى: بر اساس يافتهاى اين بزوهش مىتوان نتيجه گرفت كه هيجانخواهى بر تنوعطلى جنى جنى اثر مستقيم و غير مستقيم معنى دارى دارد. طر حوارههاى فعالشونده در رابطه مؤلفههاى هيجانخواهى و تنوع طلبى جنسى نقش ميانجى دارند.
مشخصات مقاله

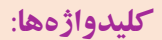

تنوع طلبى جنسى،

هيجانخو اهى،

طرحوارههاى فعالشونده

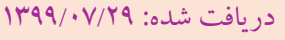
يذيرفته شده:

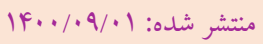

* نويسنده مسئول: عزت ديره، استاديار گرروه روانشناسى، واحد بوشهر، دانشگاه آزاد اسلامى، بوشهر، ايران.

رايانامه: Ezatdeyreh@iaubushehr.ac.ir

تلفن: $91 \mathrm{VWVM}$ 
جستجوى انواع تحريكات، از جمله لمس و نكاه كردن ساده تا خودنمايى

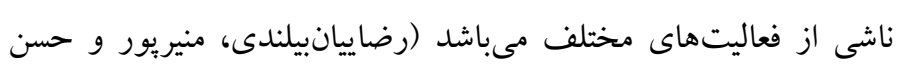

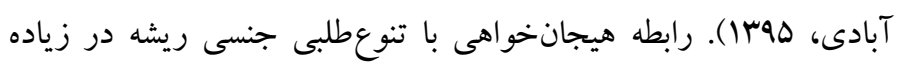

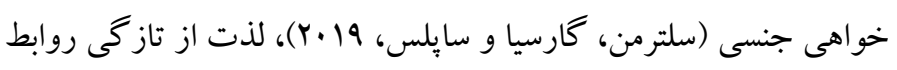

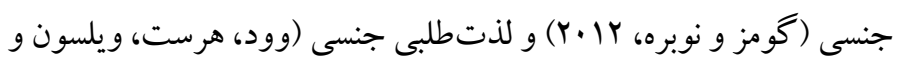

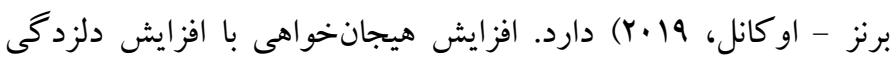
زناشويى (عمادى، ميرهاشمى و شريفى، و9٪1) و با افزايش تعارضات

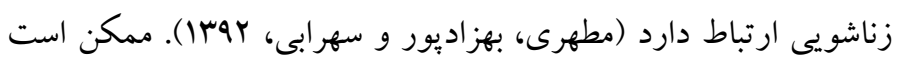

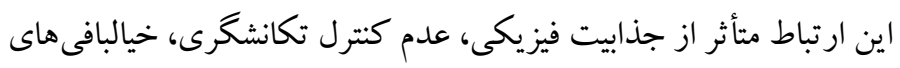

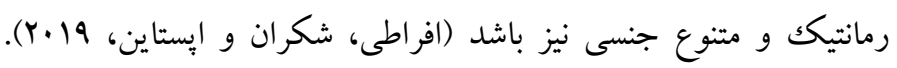

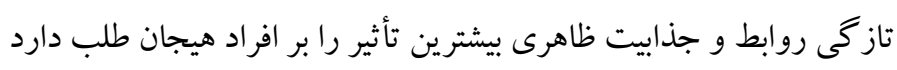
و يكى از مهمترين شاخصهايى است كه در تنوع طلبى جنسى مردان مطرح

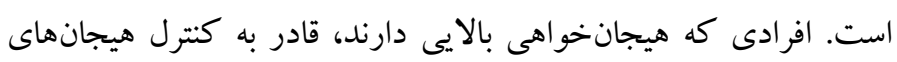

$$
\text { جنسى خود نيستند (اوتو، 19 19). }
$$

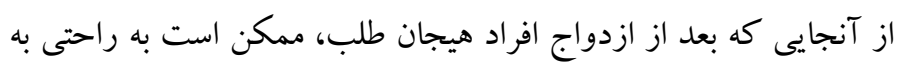

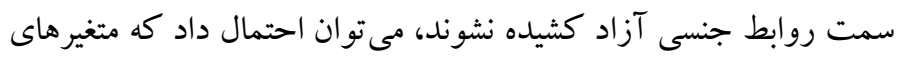
ديخرى بين دو متغير تنوعطلبى جنسى و هيجانخواهى، نقش ميانجى را رانس

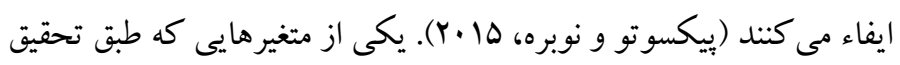

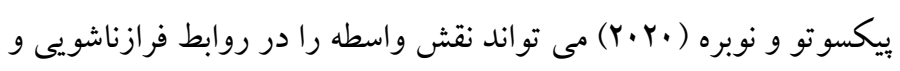

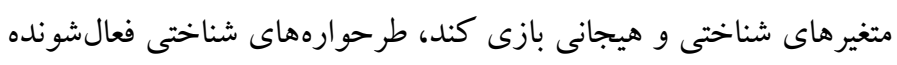

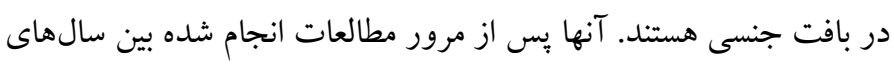

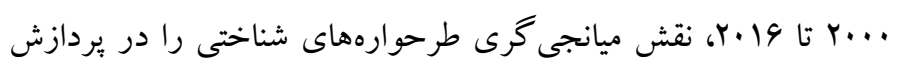

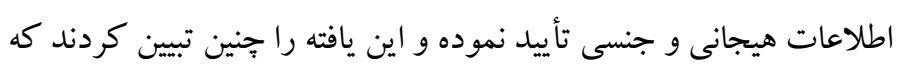

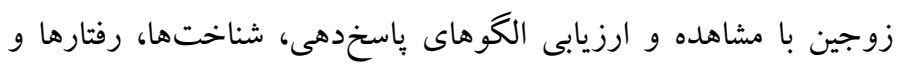
احساسات بين دو طرف در تعاملات زناشويى، به ادراكاتى دست مى بيابند

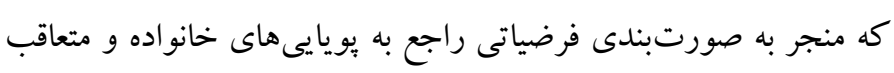

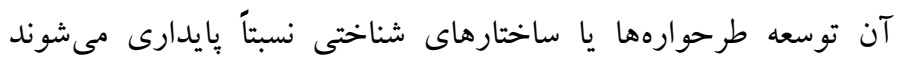

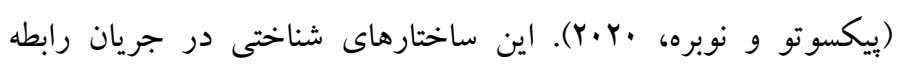

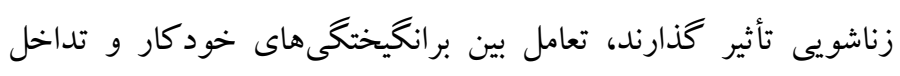

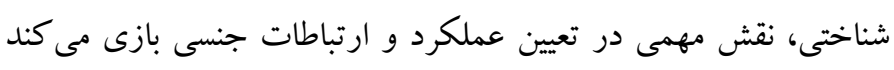

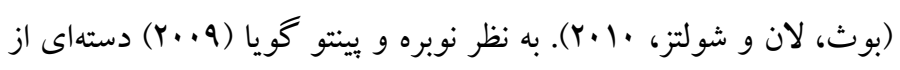

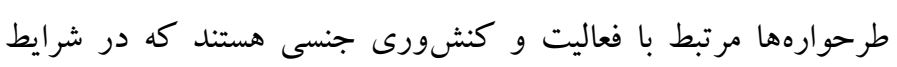

مقدمه زندكى خانوادگى با خطراتى گره خورده است كه استمرار حيات

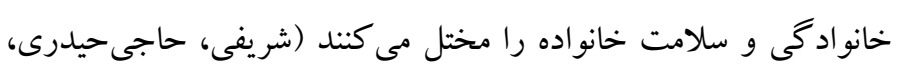
خوروش و فاتحىزاده، (اجا). يكى از اين خطراتى كه استمرار حيات

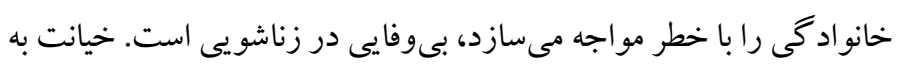

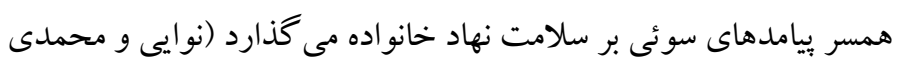

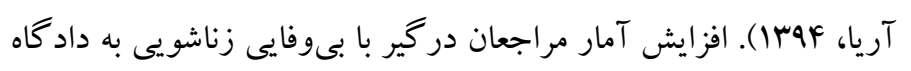

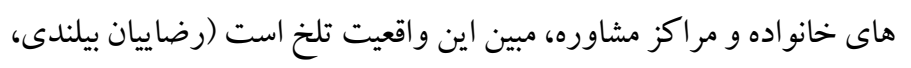

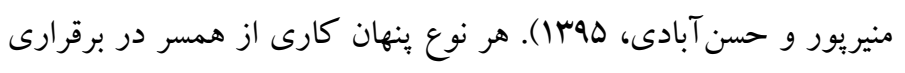

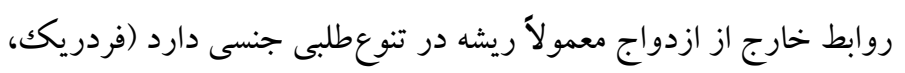

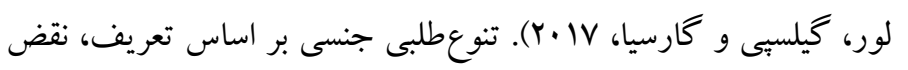

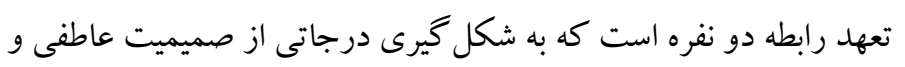

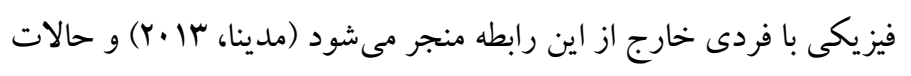

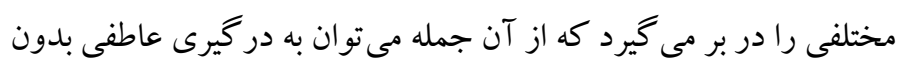

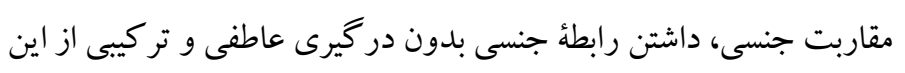

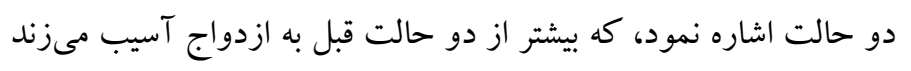

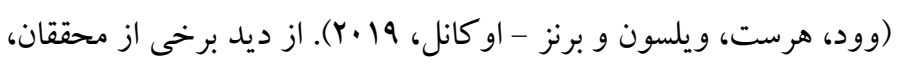
تجارب هيجانى ناشى از آميزش جنسى با فردى غير از همسر (سلترمن،

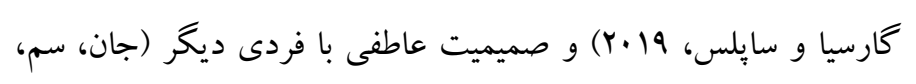

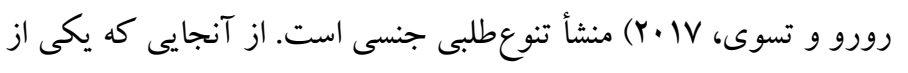

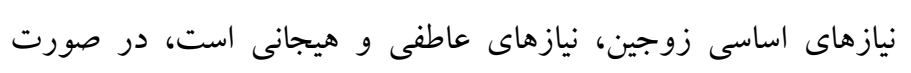
ناكامى، بى كفايتى يا احساس تحقير و تنهايى در روابط زناشويى، ممكنى نيازئ

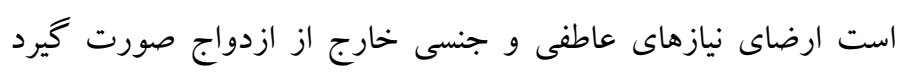

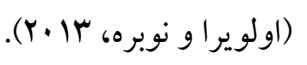
يكى از عوامل تنوع طلبى جنسى، هيجانخواهى است (خان كرمى، هوب1؛؛

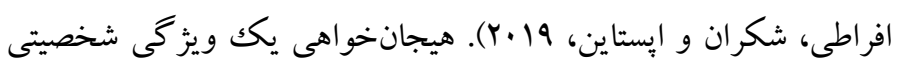

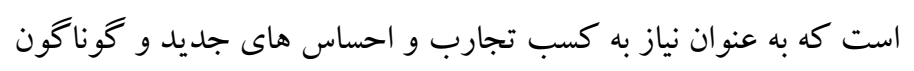

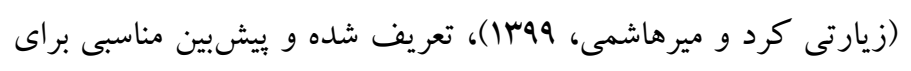

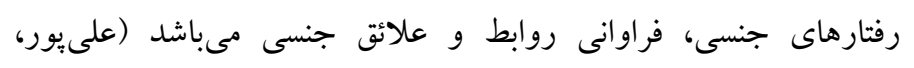

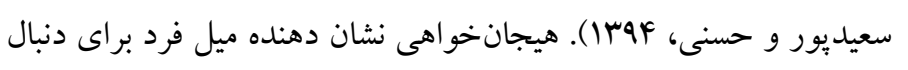

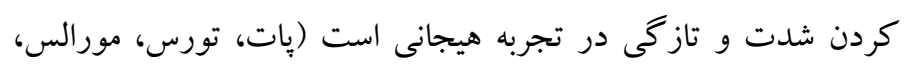

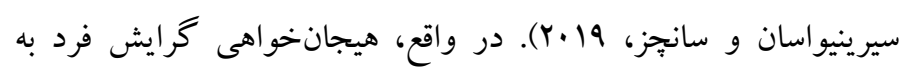


به رابطه زناشويى با همسر كاهش مى يابد به دنبال جايغزينى براى ارضاى

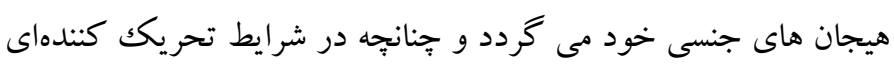

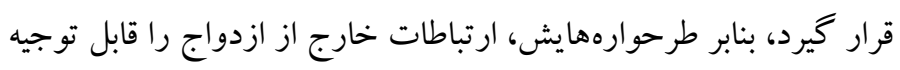

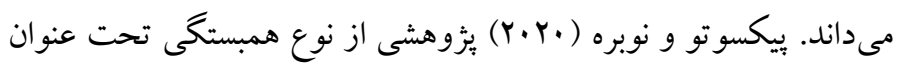

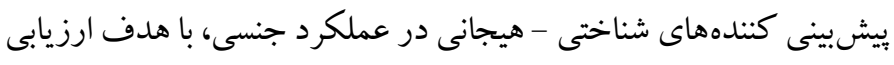
نقش ويز گى هاى شخصيتى، باورهاى جنسى، طرحو ارههاى شناختى فعال -

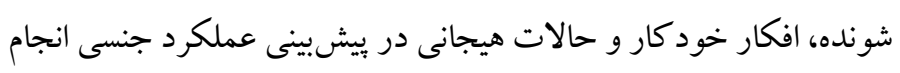

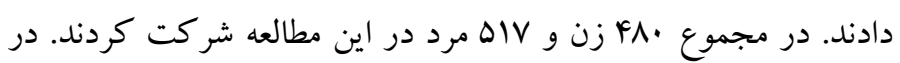

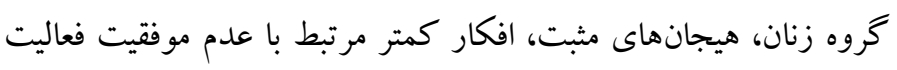

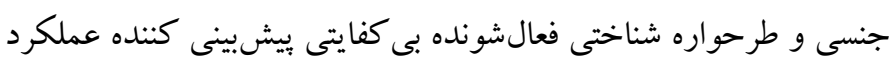
جنسى بود. در مردان نيز بايين بودن طرحو اره شناختى بـى كفايتى و افكار

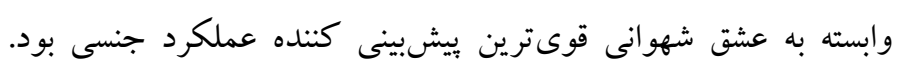

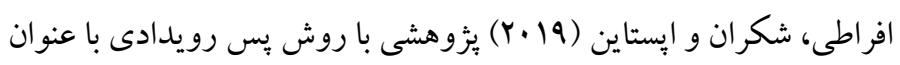
رفتار جنسى اجبارى، جرم جنسى: تفاوت در طرحوارههاى شناختى فعال -

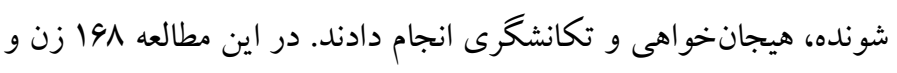

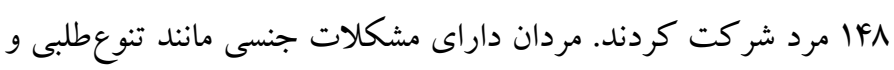

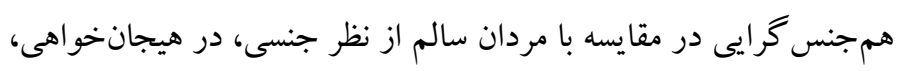
تكانشگرى و طرحوارههاى شناختى فعالشونده بـى كفايتى و طرد نمرات بيشترى كسب كردند. در زنان با مشكلات جنسى نيز در مقايسه با زنان بدون مشكلات جنسى، نمرات طرحوارههاى طرد، بى كفايتى و تنهايى به طور

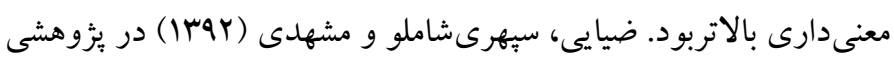
تحت عنوان رابطهى طرحوارههاى شناختى فعالشونده، افكار خودآيند

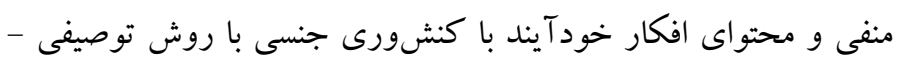
همبستكى، ها I دانشجوى متأهل زن را مورد مطالعه قرار دادند. نتايج نشان داد كنشورى جنسى توسط متغيرهاى افكار خود آيند منفى و طرحواره

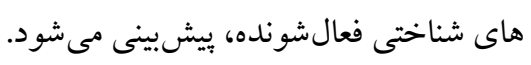

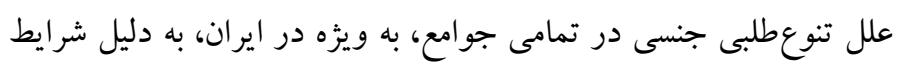

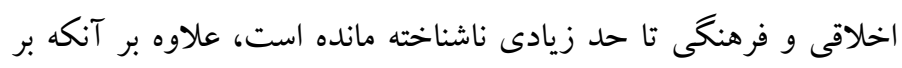

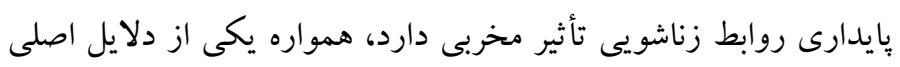
كستكگى نظام خانواده بوده است (شريفيان، صفرىنيا و علىزادهفرده،

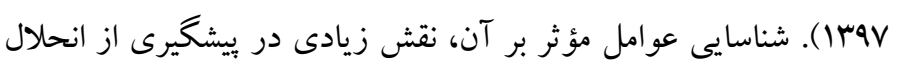

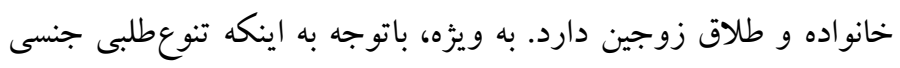

خاصى فعال مى شوند و به عنوان طرحوارههاى شناختى فعالشونده شناخته

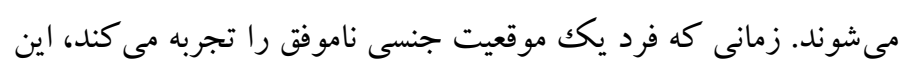

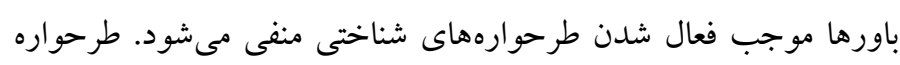

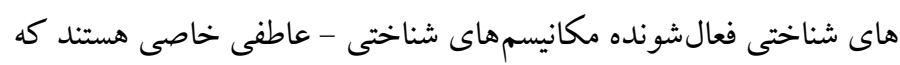
فعالسازى و هدايت ياسخ هاى هيجانى و جنسى را بر عهده دارند.

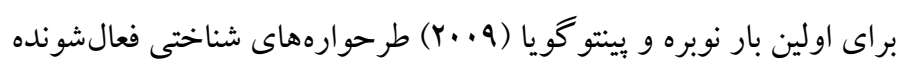
را در جهار حوزه اصلى مطرح كردند: بى كفايتى (من نسبت به ساير مردان

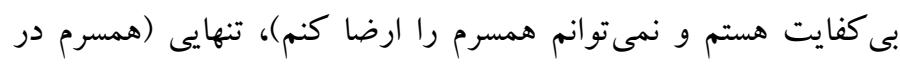

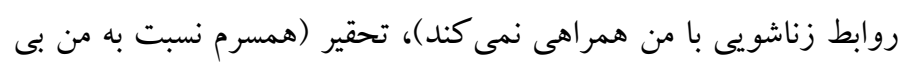

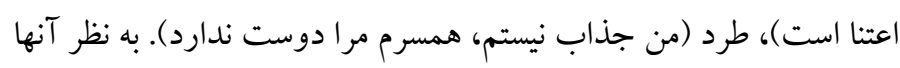
زمانى كه فرد يكك موقعيت جنسى ناموفق با همسر را تجربه مى كند،

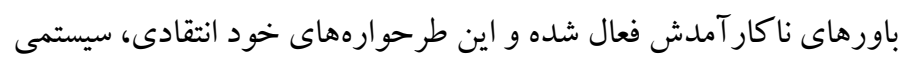

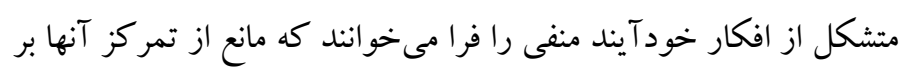
ارتباط جنسى رضايتبخش با همسر مىشود (كانتيم و نوبره، 11 أب).

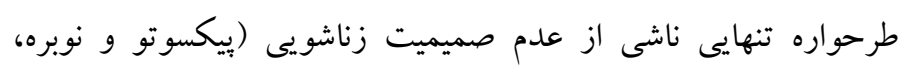

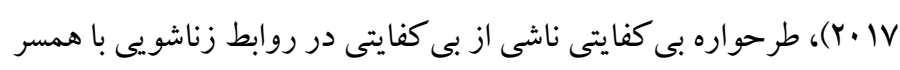

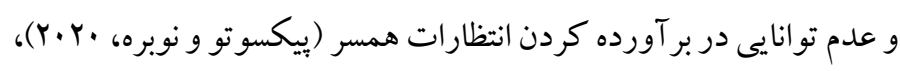
طرحواره طرد به علت عدم جذابيت و دلزدگى زناشويى (افراطى، شكران

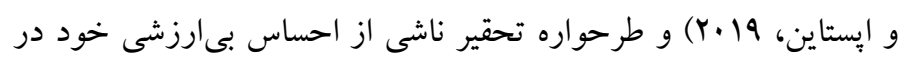

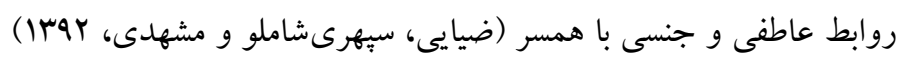

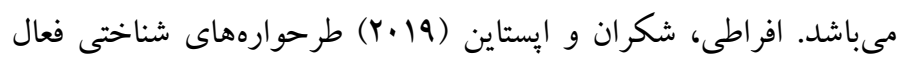

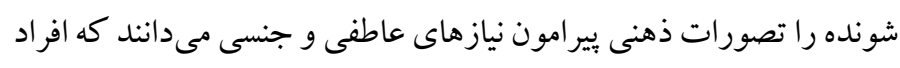
از همسر يا شريك جنسى خود دارند. در اثر عدم ارضاى اين نيازها،

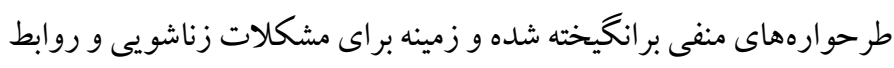

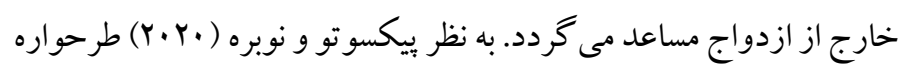

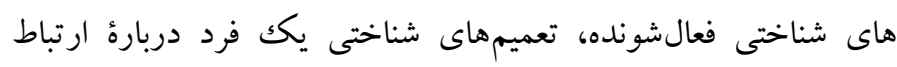

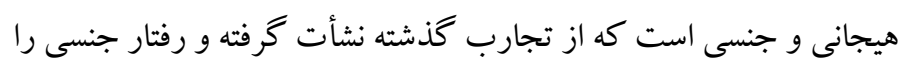
حتى بس از ازدواج هدايت مى كنند. به نظر افراطى، شكران و وإِ إستاين

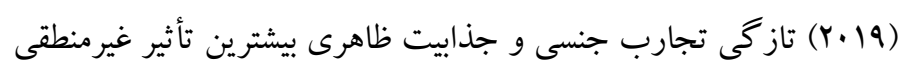

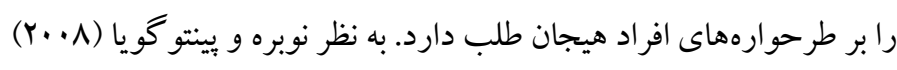

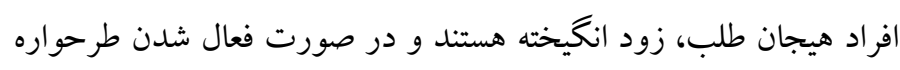

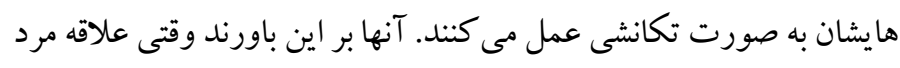


دقت كافى در تكميل برسشنامهاى تحقيقاتى بود. ابزار اصلى كردآورى در اين مطالعه سه يرسشنامه به قرار زير بود.

ب) بزإ)

برسشنامه تنوعطلى جنسى ': اين برسشنامه توسط گلاس و رايت (199Y)

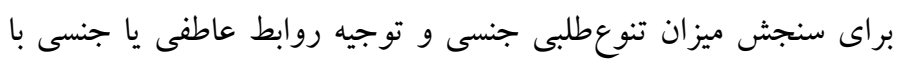

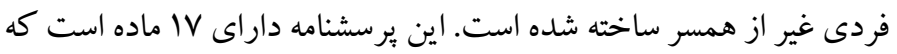

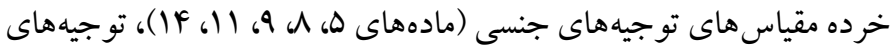

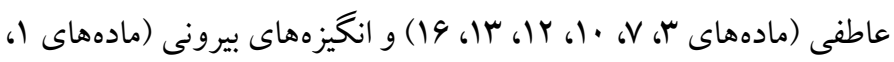

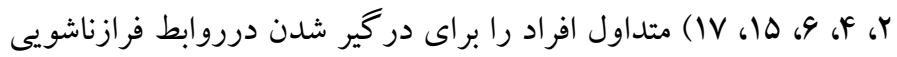
مورد سنجش قرار مىدهد. باسخخها در مقياس ه درجهاى از طيف ليكرت

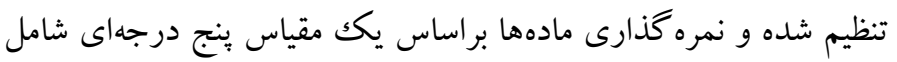

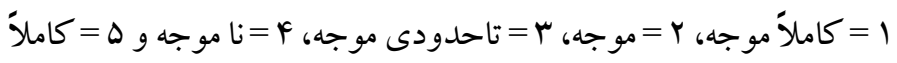
ناموجه، انجام مى يذيرد. حداقل نمره در اين برسشنامه IV و حداكثر نمره آن هم مىباشد. كَلاس و رايت (199ץ) بايايى اين مقياس را با استفاده از

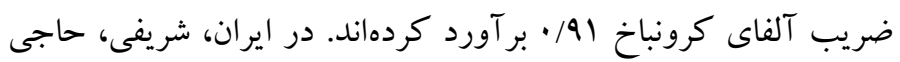

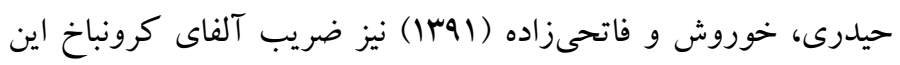

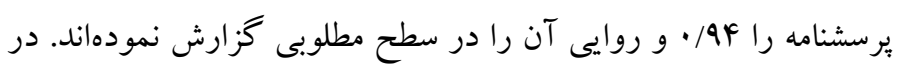

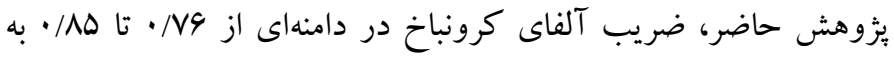

$$
\text { دست آمد. }
$$

برسشنامه برانگيختخى طرحوارههاى شناختى در بافت جنسى ؟ّ اين

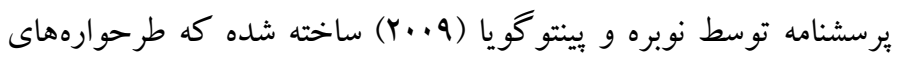

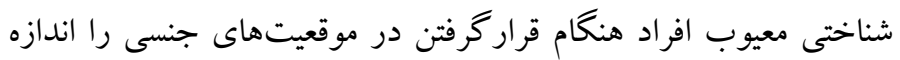

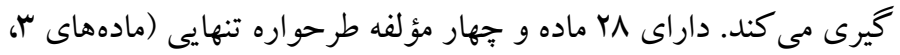

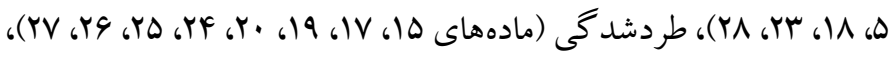

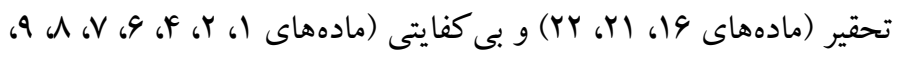

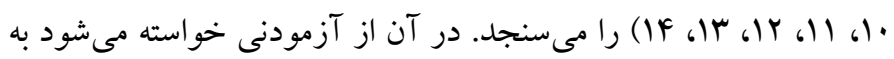
هر كدام از موارد، با توجه به گزينههاى داده شده، يعنى كاملاً اشتباه، اشتباه،

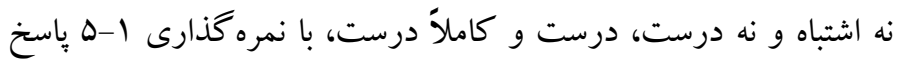

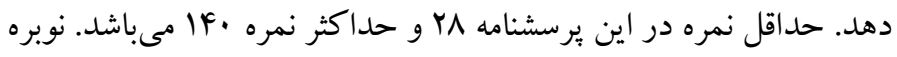

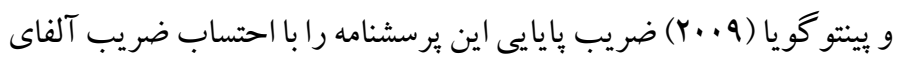

2. Questionnaire of Cognitive Schema Activation in Sexual Context (QCSASC)
تعهل زناشويى را در معرض خطر قرار داده و زمينه زوال روابط زناشويى را

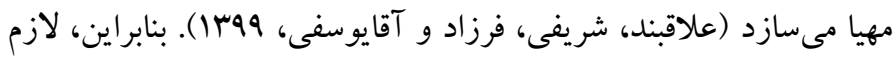
است تا علل زيربنايى ايجاد آن شناسايى شده و روابط مستقيم و و

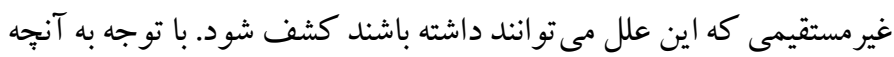
ذكر شد، سؤال اساسى بُزوهش حاضر اين است كه آيا مدل بيشنهادى تأثير

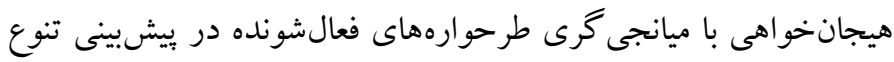
طلبى جنسى مردان متأهل مراجعه كننده به مراكز مشاوره شهر شير از برازش خو.بى دارد؟

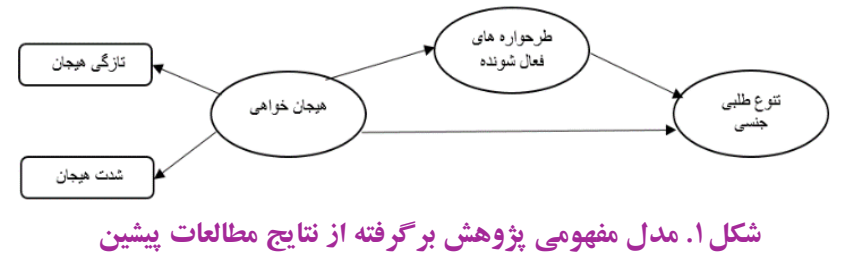

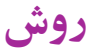
الف) طرح :ثووهش و شر كت كنند كان: اين مطالعه توصيفى - همبستخى و از نوع مدل معادلات ساختارى است. جامعه يثزوهش حاضر تمامى مردان

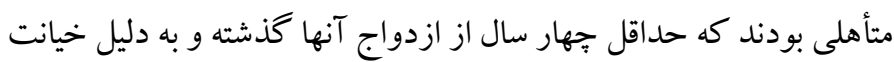
زناشويى و مشكلات جنسى، به مراكز مشاوره شهر شيراز از بهمن ماه سال

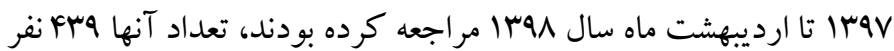
بود. از بين مراكز مشاوره موجود در شيراز 9 مركز حاضر به همكارى با

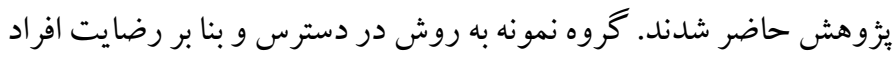

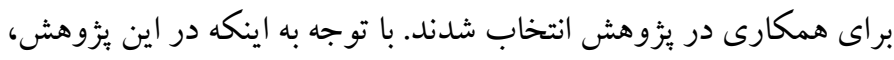
متغير بيشبين هيجانخو اهى شامل دو مؤلفه، متغير ميانجى طرحوارههاى

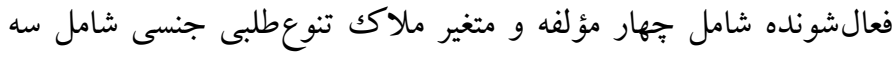

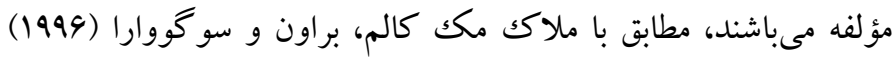

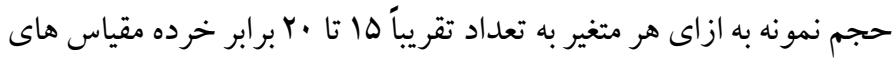

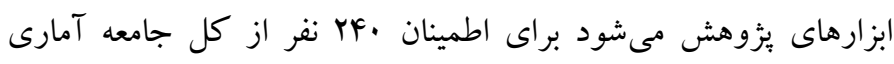

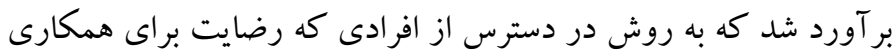

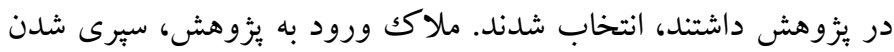

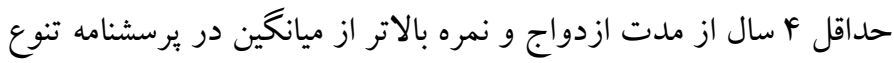

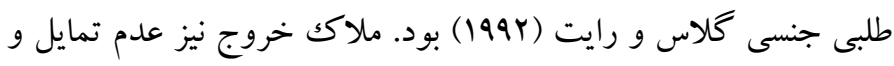

1. Sexual variety scale 
(TV9)

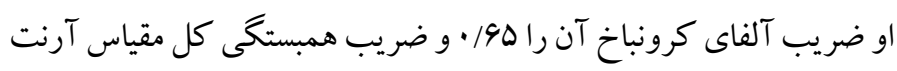

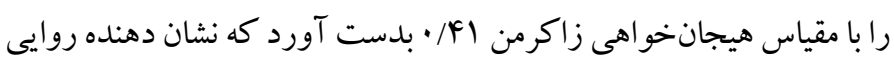

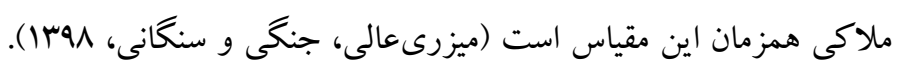

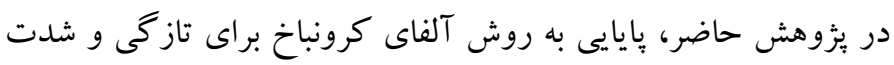

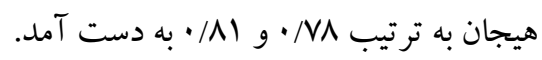

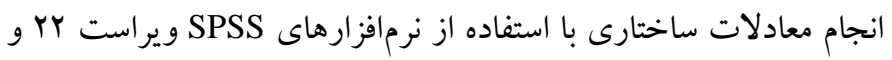

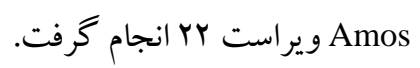

\section{يافته ها}

با توجه به دادههاى به دست آمده و با استفاده از روشهاى آمار توصيفى به بررسى مشخصات دمو گر افيك برداخته شده است: سن آزمودنى ها بين

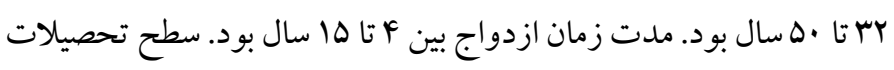

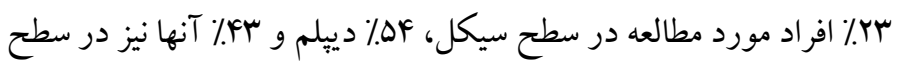
ليسانس بود. شاخص هاى توصيفى متغيرهاى بزوهش در جدول زير

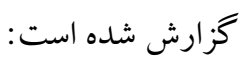

\begin{tabular}{|c|c|c|}
\hline انحراف معيار & ميانگين & متغير \\
\hline$r / 19$ & IV/rA & طرحواره تنهايى \\
\hline $1 / \Delta 9$ & $V / 10$ & طرحواره تحقير \\
\hline$r / r I$ & $1 N / T^{4}$ & طرحواره طرد \\
\hline$f / 90$ & $r \Delta / \Phi v$ & طرحواره بى كفايتى \\
\hline$r / Y F$ & $r q / \mu_{q}$ & تاز گى هيجان \\
\hline$r / 19$ & $r I / F \Delta$ & شدت هيجان \\
\hline$\varphi / \mu \Delta$ & $G \% / \Delta V$ & هيجانخو اهى \\
\hline ৭/^৭ & $\Delta Q / / T$ & تنوعطلبى جنسى \\
\hline
\end{tabular}

براى تعيين ميزان رابطه متغيرها، ضريب همبستگى بين متغيرهاى مورد يثزوهش محاسبه شد كه نتايج آن در جدول r بنشان داده شده است:

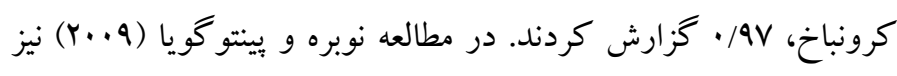

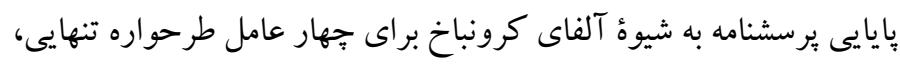

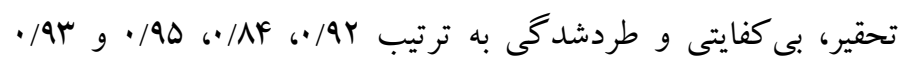

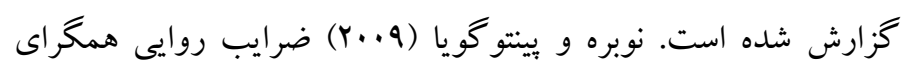

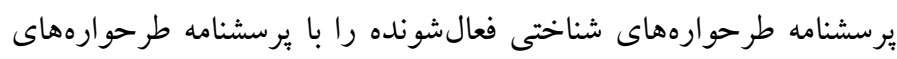

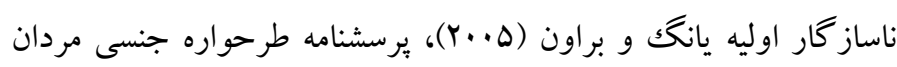

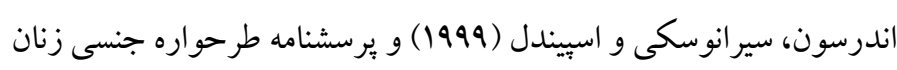

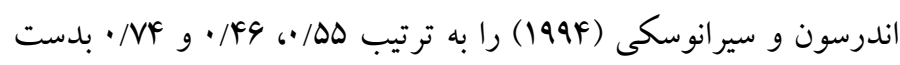

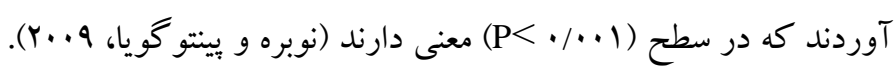

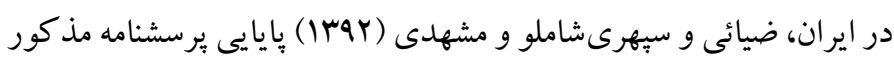

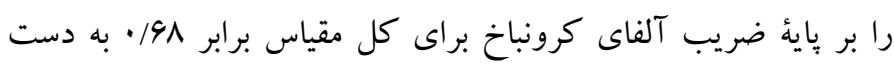

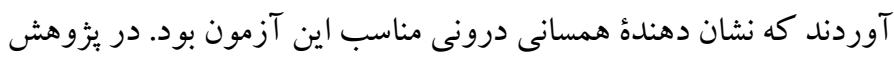

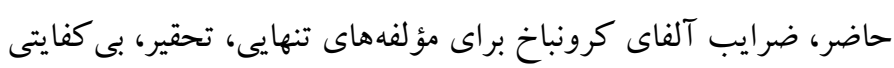

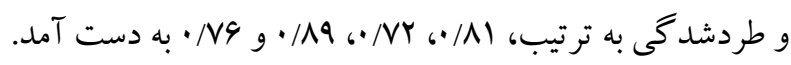

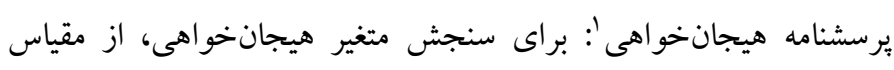

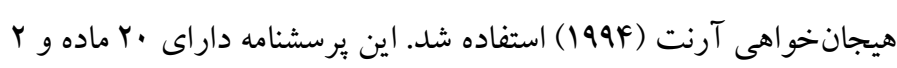

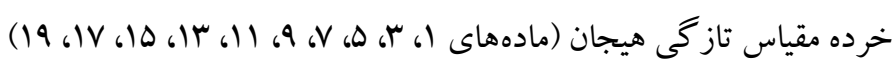

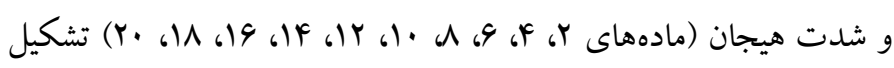

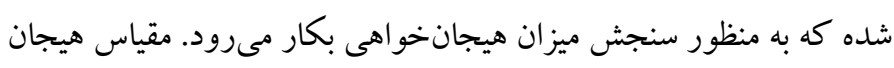

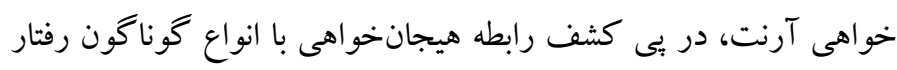

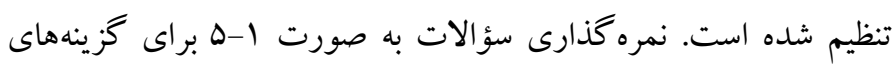

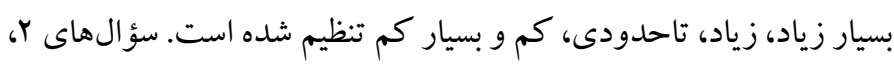

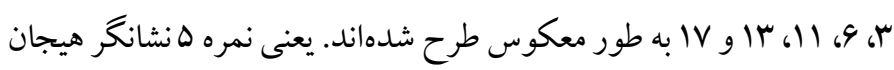

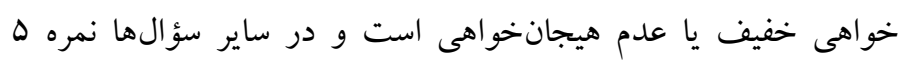

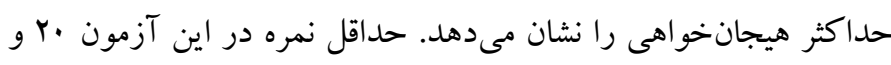

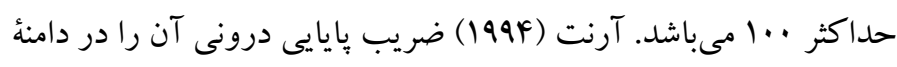

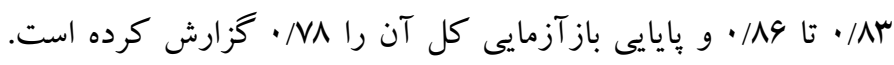

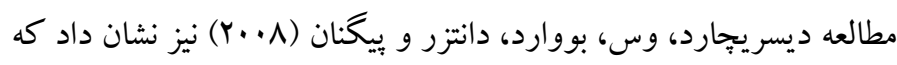

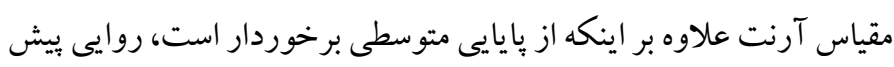

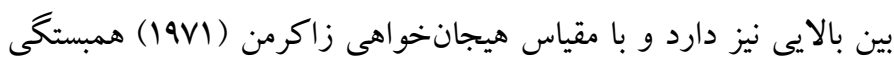

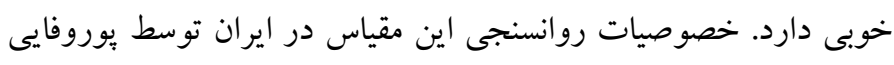

${ }^{1}$.Sensation seeking scale 


\begin{tabular}{|c|c|c|c|c|c|}
\hline تنوع طلبى & بى كفايتى & طرد & تنهايى & تحقير & متغيرها \\
\hline **./DMr & $* * . / Y \wedge q$ & $* * \cdot / \Delta V r$ & $* * . /$ YVA & $* * . / 949$ & شدت هيجان \\
\hline$* * . / 4 r$. & $* * / 419$ & $* * . / 491$ & $* * . / Y q 1$ & **./rar & تاز گیى هيجان \\
\hline * * * & $* * \cdot /$ \&ar & $* *$. FrF & **./YrA & $* * \cdot / \Delta \Delta F$ & هيجانخواهى (كل) \\
\hline 1 & **./YGT & $* * \cdot / r \wedge \mid$ & **./Tar & $* * . / T V$ & تنوعطلبى جنسى \\
\hline
\end{tabular}

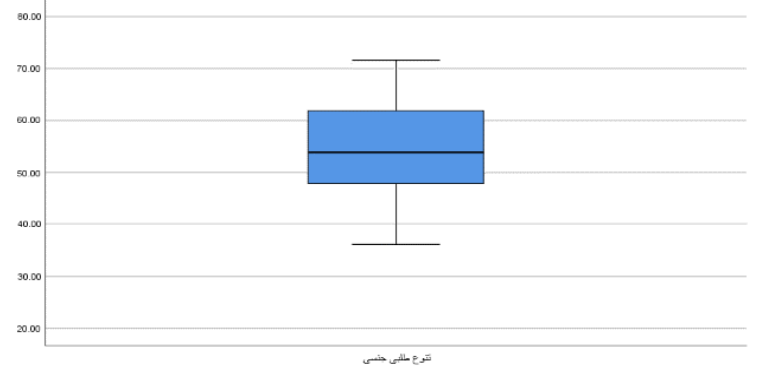

نمودار r. نتايج آزمون باكس ويسكر براى تنوع طلبى جنسى

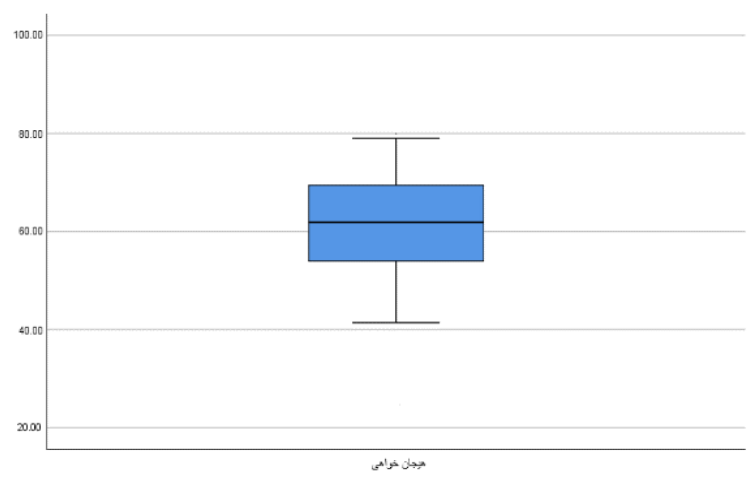

نمودارّا. نتايج آزمون باكس ويسكر براى هيجانخواهى

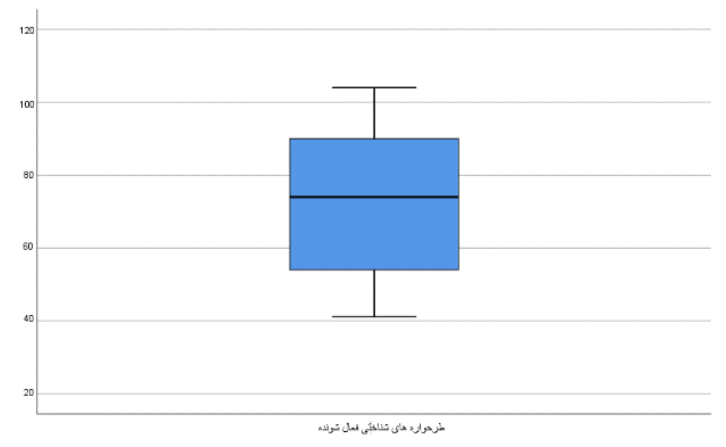

نمودارع. نتايج آزمون باكس ويسكر براى طرحوارههاى فعالشونده

همانكونه كه مشاهده مى شود نمودارهاى Y، برو \& نشان مى دهند، در توزيع متغيرهاى مورد يزوهش، داده يرتى وجود ندارد. يس از بررسى و تأييد

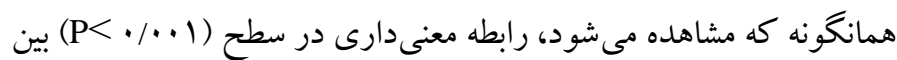
تنوع طلبى جنسى، هيجانخواهى و طرحوارههاى شناختى فعال شونده وجود دارد. قبل از ارزيابى مفروضههاى مدل يابى معادلات ساختارى، نرمال بودن توزيع دادهها با استفاده از آزمون كلمو گروف - اسميرنوف مورد محاسبه قرار گرفت. مقادير Z براى تنوعطلى جنسى (199r/)، هيجانخواهى (TM/9) و طرحوارههاى شناختى فعالشونده نيز (VY9/•) به دست آمد كه همه آنها داراى سطح معنادارى بالاتر از ه•• • بوده و بيانگ نرمال بودن توزيع دادهها مىباشد. براى بررسى عدم هم خطى بين متغيرهاى مستقل نيز از شاخص تولرانس وVIF يا تورم واريانس استفاده شده است. شاخص

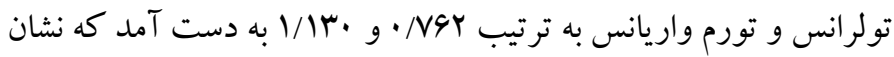
مى دهد فرض برقرارى عدم هم خطى متغيرهاى مستقل رعايت شده است. نتيجه محاسبه آزمون دوربين واتسون نيز سها/ به دست آمد كه نشان مى

دهد مفروضه استقلال خطاها نيز در بين دادههاى يزوهش برقرار است. نرمال بودن براكندكى نمرات متغير وابسته به عنوان بيش شرط ركرسيون خطى بررسى شد، نتايج آن در نمودار ا ارائه شده است:

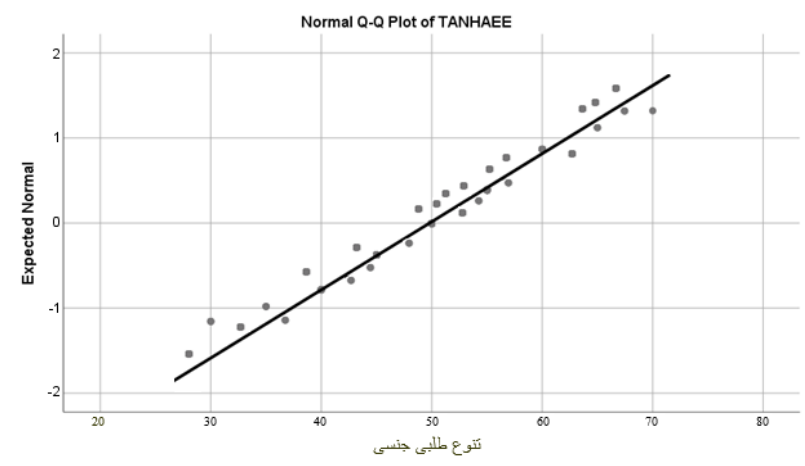

نمودار ا. ير اكند

بر اساس نمودار ا فرض خطى بودن تأييد مى گردد. به منظور شناسايى داده هاى برت، آزمون باكس ويسكر براى متغيرهاى بثزوهش محاسبه كرديد، نتايج اين محاسبات در نمودارهاى r، ب و F نشان داده شده است: 
شاخص هاى مذكور تقريباً كمتر از 9/ • بود كه نشان مىدهد مدل بثزوهش

$$
\text { حاضر، برازش مناسبى دارد. }
$$

جدول F به اثر مستقيم مؤلفههاى هيجانخواهى و طرحوارههاى شناختى فعالشونده اشاره دارد. همانكونه كه ملاحظه مى گردد مؤلفههاى هيجان خواهى بر طرحوارههاى فعالشونده اثر مستقيم معنىدارى ( ( P دارند. بطور كلى، مدل تأثير هيجان بر طرحوارههاى شناختى فعالشونده معنىدار است. اثر تازگى و شدت

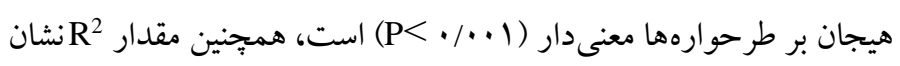
مىدهد تازگى هيجان بر طرحواره طرد بيشترين تأثير را دارد. تازگى و و شدت هيجان بر تنوعطلى جنسى نيز اثر مستقيم معنى دارى ( ( P > دارند. نتايج تحليل رگرسيون جند متغيره مندرج در جدول ه نشان مىدهد طرحوارههاى فعال شونده در بافت جنسى بر تنوعطلى جنسى مردان متأهل

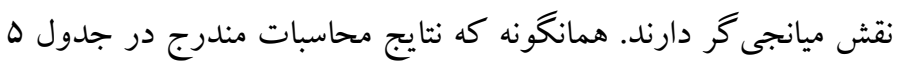

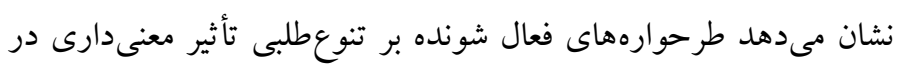
سطح (1 ( P<) دارند. طرحواره تنهايى بر تنوعطلى جنسى بالاترين اثر
بيشفرض ها، تحليل مدل انجام شد. شاخص هاى برازندگى مدل محاسبه و در جدول ب خلاصه شده است:

جدول ب. شاخصهاى برازش حاصل از تجزيه و تحليل دادهها

\begin{tabular}{|c|c|c|c|}
\hline مقادير يس از تصحيح & مقادير قبل از تصحيح & مقادير قابل قبول & آزمون \\
\hline$r / \wedge q$ & $F / 9 \mathrm{~V}$ & $>r$ & $\chi^{2 / d f}$ \\
\hline .1 .91 & $\cdot / \cdot \mathrm{VI}$ & $<\cdot / \cdot \wedge$ & RMSEA \\
\hline.$/ 9.4$ & - & $<\cdot / 9$ & GFI \\
\hline.$/ 91$. & - /AVQ & $<\cdot / 9$ & AGFI \\
\hline$. / 9 / F$ & . & $>\cdot / 9$ & CFI \\
\hline
\end{tabular}

نتايج جدول ץ نشان مىدهد كه مقدار RMSEA برابر با 91٪ • به دست آمد كه اين مقدار كمتر از ^•• • است و نشان دهنده اين است كه ميانكين مجذور خطاهاى مدل مناسب است و مدل قابل قبول مىباشد. همجينين نسبت كاى دو به درجه آزادى Y/A9 به دست آمد كه كمتر از ب است و در

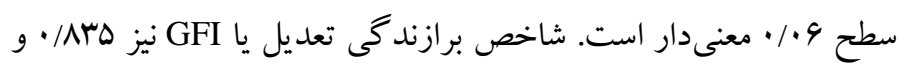
شاخص نكويى برازند

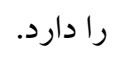

\begin{tabular}{|c|c|c|c|c|c|}
\hline $\mathrm{P}$ & $\mathrm{t}$ & $\mathrm{R}^{2}$ & B & B & متغير \\
\hline . & r/9Ar & $\cdot / \cdot \wedge \Delta$ &.$/ 19 F$ & & تازگى هيجان بر طرحواره تنهايى \\
\hline.$/ \cdot F$ & $1 / 999$ & $\cdot / l \Delta F$ & $\cdot / 1 \Delta \wedge$ & $\cdot /|V|$ & تازگى هيجان بر طرحواره تحقير \\
\hline$\cdot 1 \cdots$ & $11 / 4 F q$ & & .199 & .1909 & تاز كى هيجان بر ه \\
\hline$\cdot 1 \cdots$ & $V / 4 \cdot q$ & $\cdot / \mathrm{Vr}$ & $\cdot /$ YM & $\cdot / \mathrm{VIV}$ & تاز گى هيجان بر طرحواره بى كفايتى \\
\hline$\cdot 1 \cdots$ & $\Delta / \wedge q F$ & $\cdot / \cdot$ VA & $\cdot$ TYFD & •/VMG & شدت هيجان بر طرحواره تنهايى \\
\hline$\cdot 1 \cdots$ & $\Lambda / 9 V F$ & $\cdot / 4 \cdot \wedge$ & 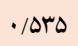 & $1 / \Delta \Delta r$ & شدت هيجان بر طر \\
\hline$\cdot / \cdots F$ & r/OHA & 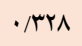 &.$/ 19 V$ & $\cdot / M F \Delta$ & شدت هيجان بر طرحواره طرد \\
\hline$\cdot / \cdots$ & $\mathrm{V} / \Lambda \Delta \Lambda$ & $\cdot / \cdot \wedge f$ & $\cdot /$ Far & $\cdot / \mathrm{ANV}$ & شدت هيجان بر طرحواره بى كفايتى \\
\hline$\cdot 1 \cdots$ & G/9FV &.$/ 1 V 9$ & $\cdot / r Y$ & $\cdot / r V I$ & تازگى هيجان بر تنوعطلى جنسى \\
\hline$\cdot 1 \cdots$ & F/DGY & $\cdot$ / YAF & $\cdot / r \cdot V$ & 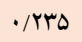 & شدت هيجان بر تنوعطلبى جنسى \\
\hline
\end{tabular}

\begin{tabular}{|c|c|c|c|c|c|}
\hline $\mathrm{P}$ & $\mathrm{t}$ & $\mathrm{R}^{2}$ & $\beta$ & $\mathrm{B}$ & 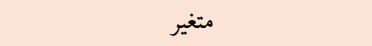 \\
\hline.$\cdots$ & $9 / 014$ &.$/ 1 \Delta F$ & . raY & $\cdot / r \cdot \Delta$ & طرحو اره تنهايى برتنوع طلبى جنسى \\
\hline$\% \cdots$ & $f / 111$ & $\cdot /$ Irv & $\cdot /$ YAD &.$/ 191$ & طرحواره تحقير برتنوعطلى جنسى \\
\hline$\cdot \cdots$ & r/GTV &.$/ 1 F Q$ & $\cdot /$ IV & $\cdot r \cdot r$ & طرحواره طرد بر تنوعطلبى جنسى \\
\hline.$/ \cdot 1$ & r/Yal & .1 .99 & $\cdot / 199$ & $\cdot /$ rar & طرحواره بى كفايتى بر تنوعطلبى جنسى \\
\hline
\end{tabular}


فعالشونده نيز وجود دارد كه ميزان آن با اثر غير مستقيم در جدول 9

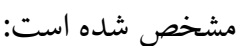

در مورد تأثير هيجانخواهى بر تنوططلى جنسى، علاوه بر اينكه يكك اثر

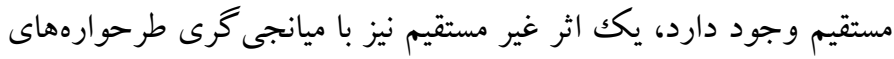

\begin{tabular}{|c|c|c|c|c|c|}
\hline $\mathrm{P}$ & $\mathrm{t}$ & اثر كل & اثر مستقيم & اثر غيرمستقيم & متغيرها \\
\hline$\cdot \cdots$ & V/MFA & $\cdot /$ Ar. & . & $\cdot / 1 \cdot r$ & تاز گى هيجان طم طرحواره فعالشونده ڤء تنوعطلبى \\
\hline$\cdot 1 \cdots 1$ & $r / 1 \wedge q$ & $\cdot / r \cdot 1$ & $\cdot / 1 r$ & $\cdot / \cdot M$ & شدت هيجان ڤم طرحواره فعالشونده ڤم تنوعطلبى \\
\hline
\end{tabular}

معادلات ساختارى انجام شد، نتايج نشان داد مدل از برازش مناسبى

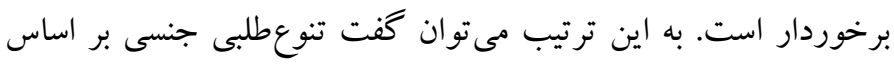

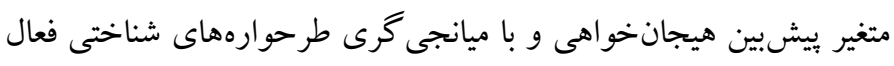

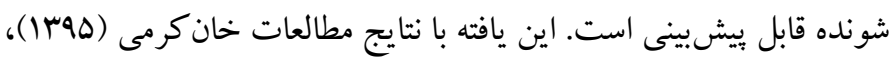

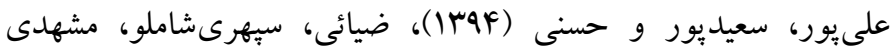

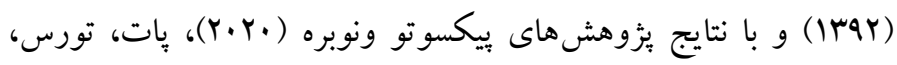

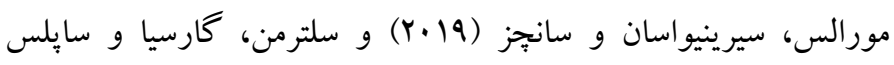

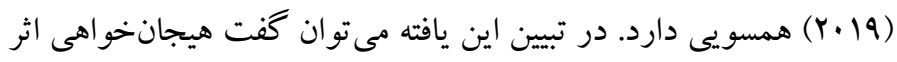
مستقيم و غير مستقيم معنى دارى با ميانجى گرى طر حوارههاى شناختى فعال شونده بر تنوع طلبى جنسى دارد كه مى تواند حاكى از تأثير بر فشار تمايلات

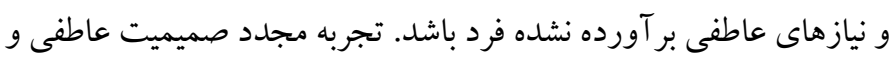
جنسى، جيزى كه ديخر آن رادر زند

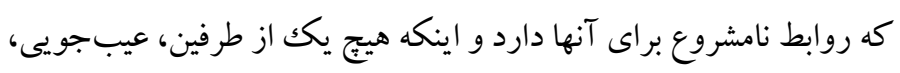

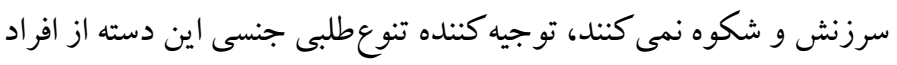

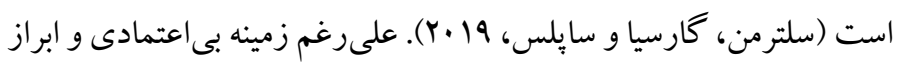
هيجان و عاطفه محدودى كه ريشه در تجارب قبلى فرد دارد، براى ايجاد

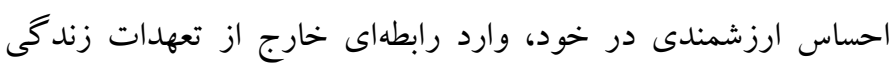

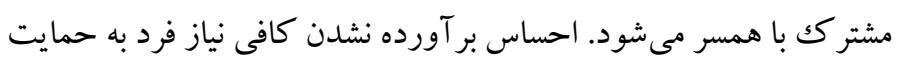

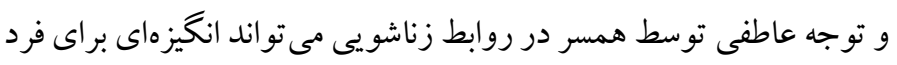
جهت زير با كذاشتن تعهل و وفادارى به همسر ايجاد كند.

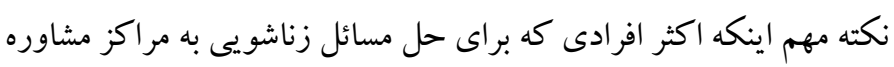

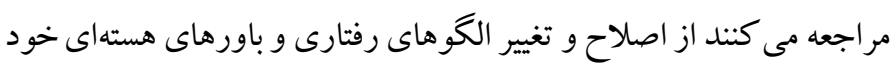

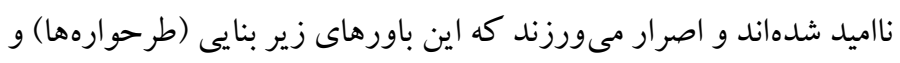
رفتارها به صورت جزء جدايىنايذير وجودشان است و در نتيجه نمى توانند

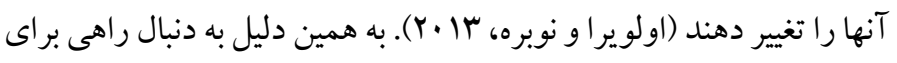

همانطور كه در جدول 9 مشاهده مى شود اثر مستقيم، غير مستقيم و اثر كل ابعاد هيجانخو اهى بر تنوعطلبى جنسى معنىدار مىباشد. اثر غير مستقيم

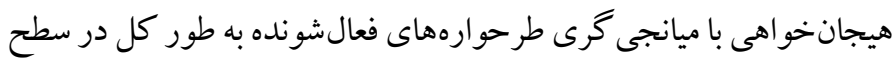

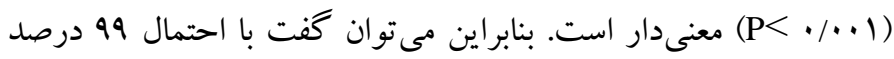
اطمينان، طرحوارههاى شناختى فعالشونده در رابطه بين هيجانخو اهى و وانى

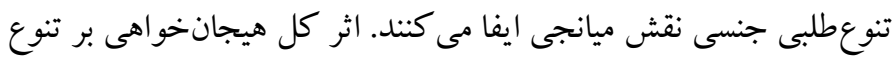

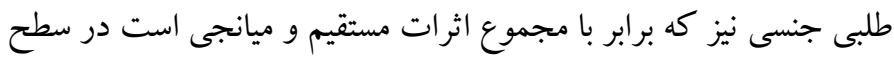

$$
\text { (P< معنى دار مىباشد. }
$$

بر اساس محاسبات فوق، مدل نهايى معادلات ساختارى بيشبينى تنوعطلبى

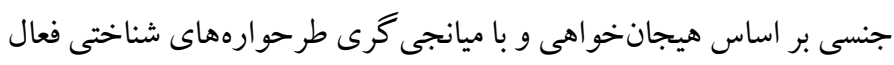

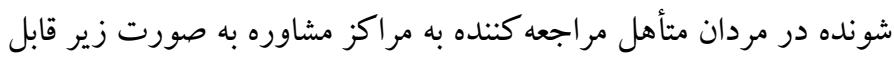
ترسيم است:

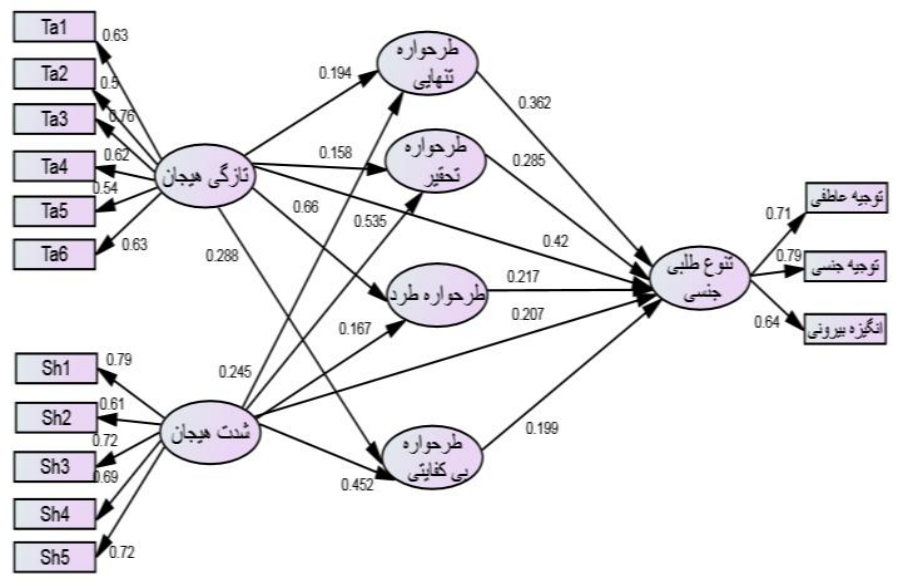

شكل r. مدل نهايع يخوهش

بحث و نتيجه تيرى هدف يروهش حاضر بيشيينى تنوعطلبى جنسى بر اساس هيجانخو اهى با

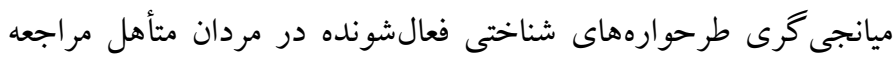
كننده به مراكز مشاوره شهر شيراز بود. تحليل مدل به روش مدليابى 
طلبى با برانخيختخى طرحوارههاى شناختى تأثير معنىدارى بر تنوع طلبى

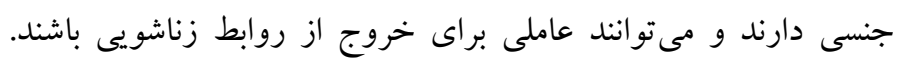

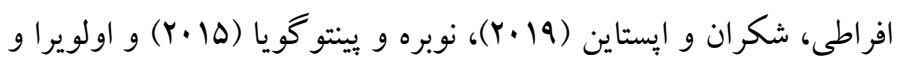

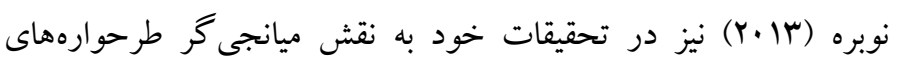

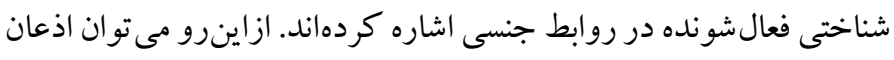

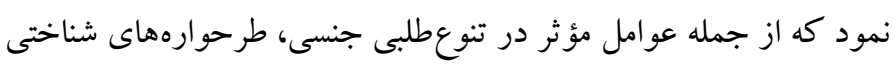

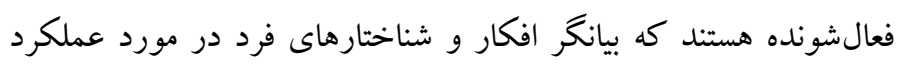

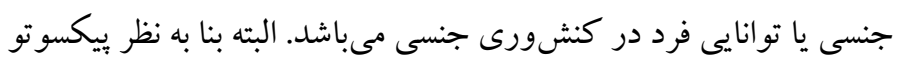

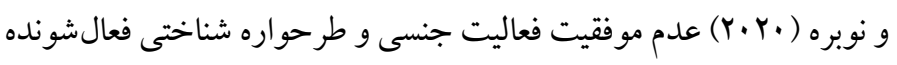
بى كفايتى بيشيينى كننده عملكرد جنسى هستند. البته، طرحوارههاى فعال

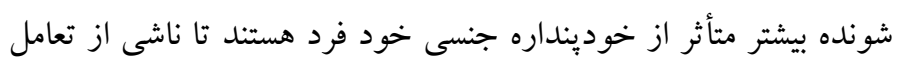

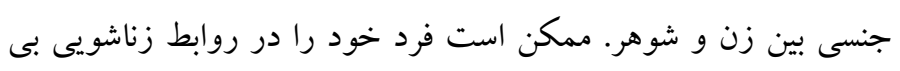

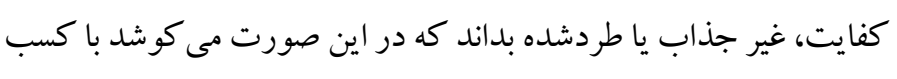
تجارب متنوع و جديد، ضمن برطرف كردن نياز جنسى، احساس و تصور

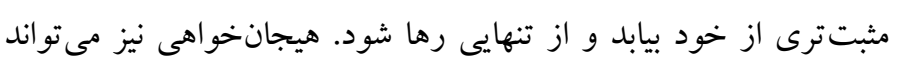
طر حوارههاى بى كفايتى، تحقير، تنهايى و طردشدگى رانى را برانخيخته كند.

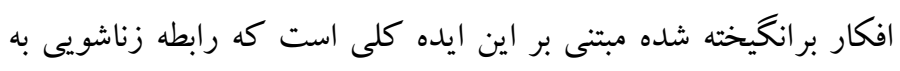

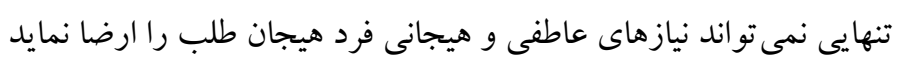

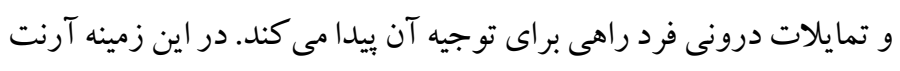

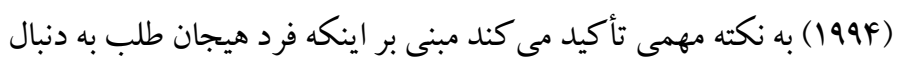

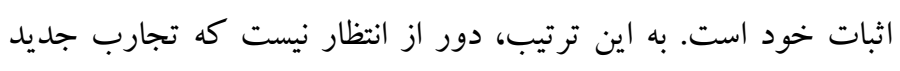

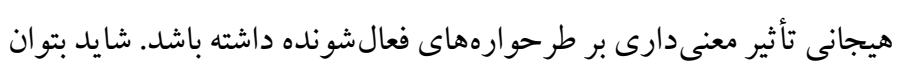

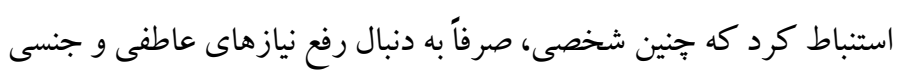

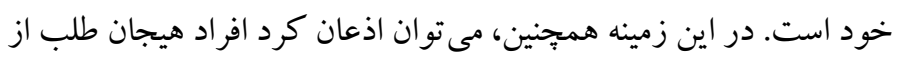
ريسك كردن و تجارب تازه جنسى استقبال مى كنند (ييكسوتو و نوبره،

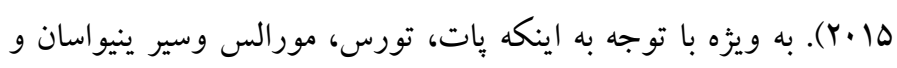

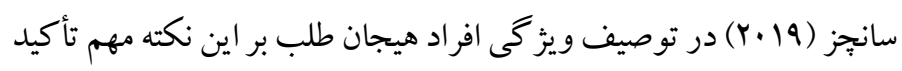

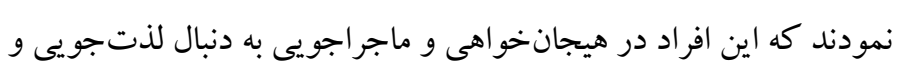

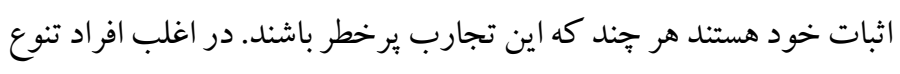

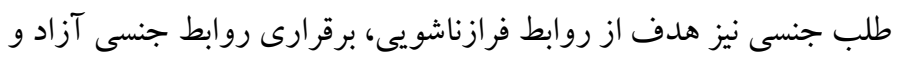
نامحدود است. آنها جنين مطرح كردند كه هيجانخواهى در افراد بسيار متفاوت است، به نظر مىرسد كه نظام شناختى و عاطفى هر فرد بر بايه اين
كاهش فشارهاى روانى، تغيير شرايط زندگى زناشويى با همسر، كاهش يا

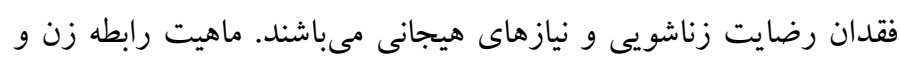

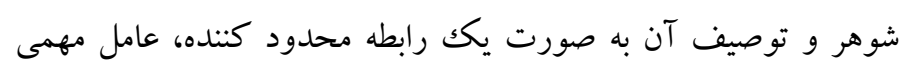

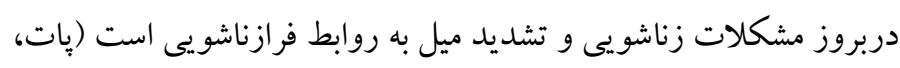

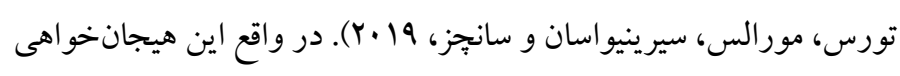
و طرحوارههاى آنها است كه عامل تنوعطلبى جنسى است و نارضايتى از روابط زناشويى و عدم ارضاى نيازهاى عاطفى و جنسى تحريك كننده ارهاي

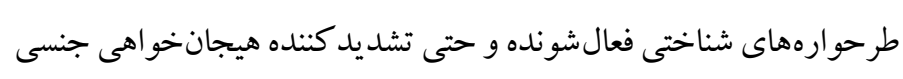

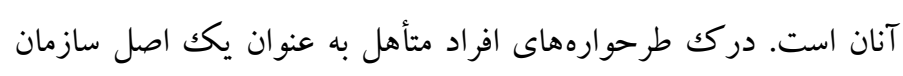
بخش، براى دركى تجارب زندكى زناشويى ضرورى است (نوبره و و

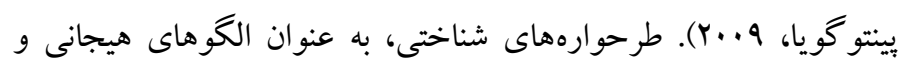

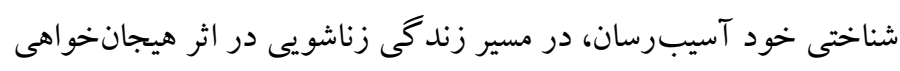

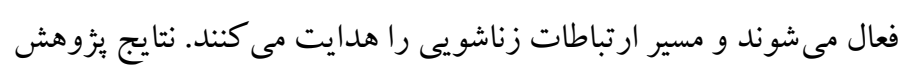

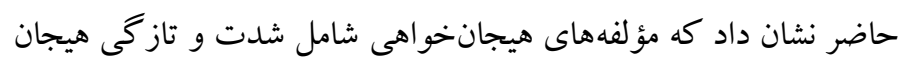
اثر مستقيم بر تنوعطلبى جنسى و طرحوارههاى فعالشونده (طرحوارههاى

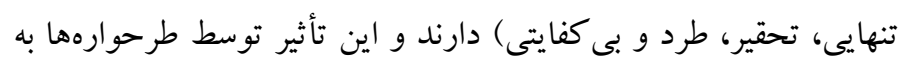
عنوان متغير ميانجى نيز بر تنوع طلبى جنسى منتقل مى شود. ضريب بت بتاى مدل

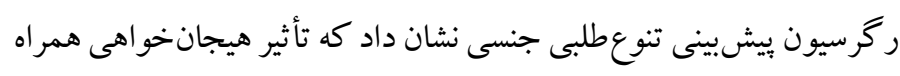

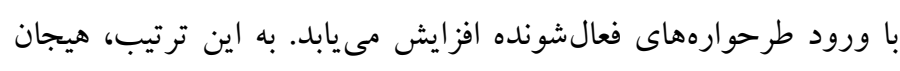

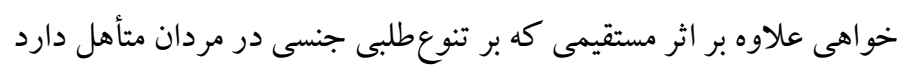

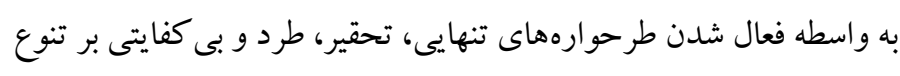

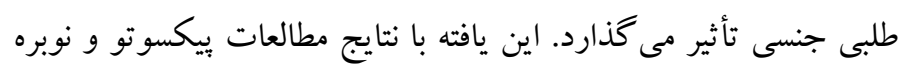

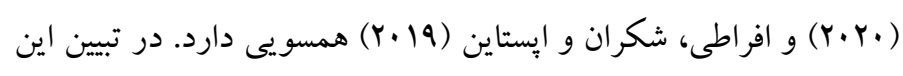

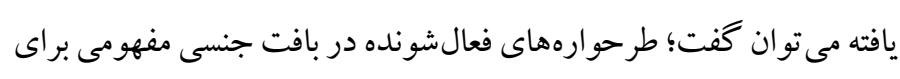

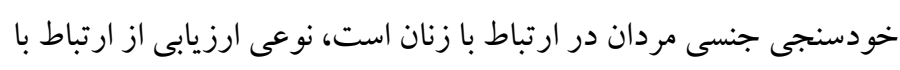

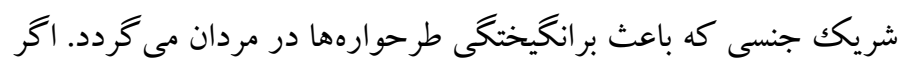

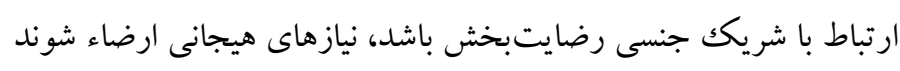

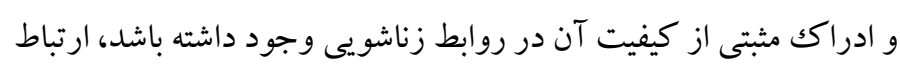
زناشويى از مسير اوليه خارج نمى شود. در غير اين صورت، اين طرحواره

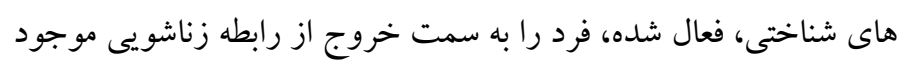

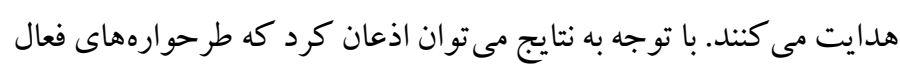
شونده در ارتباط بين هيجانخواهى و تنوع طلبى جنسى مؤثر است؛ هيجان 
مطالعات بعدى مورد يزوهش قرار دهند. بر اساس نتايج بزوهش مىتوان بيشنهاد نمود كه در جريان مشاورههاى زناشويى، تعديل هيجانخواهى و اصلاح طرحوارههاى شناختى فعالشونده (طرحواره تنهايى، تحقير، طرد و

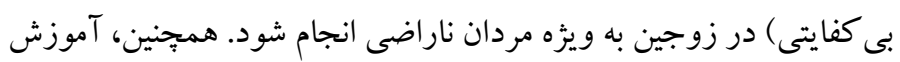
روشهاى صحيح ارضاى نيازهاى جنسى و عاطفى همسر در جريان مشاوره

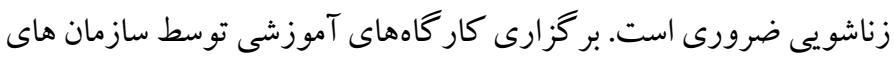

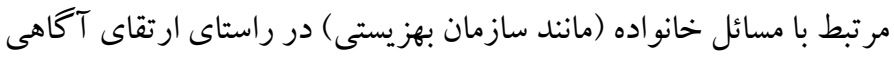
زوجين نسبت به عواقب و ييامدهاى بىوفايى زناشويى بر سلامت

$$
\text { روانشناختى اعضاى خانو اده انجام شود. }
$$

\section{ملاحضات اخلاقى} بيروى از اصول اخلاق ئوهش: در اجراى بثروهش، ضمن عدم درج نام افراد در

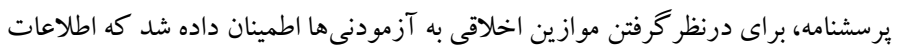

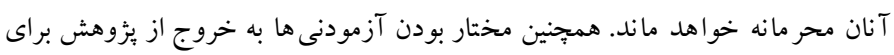
حفظ شأن و منزلت انسانى رعايت شاند.

حامى مالى: اين يُوهش در قالب رساله دكترى و بدون حمايت مالى مى مباشد.

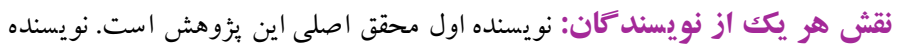

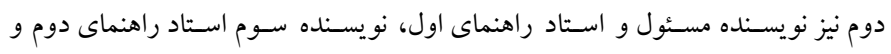
نويسنده جهارم استاد مشاور رساله مىباشند.

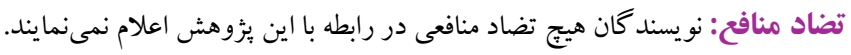

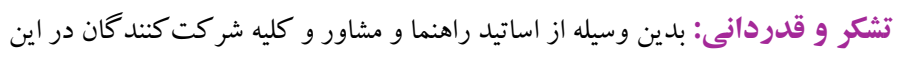
يثزوهش تشكر و قدردانى مى گردد.
خصيصه سازماندهى مىشود. به اين ترتيب، متغيرهاى شناختى و هيجانى خاصى مانند طرحوارههاى شناختى فعالشونده در ارتباط هيجانخواهى بـ باني

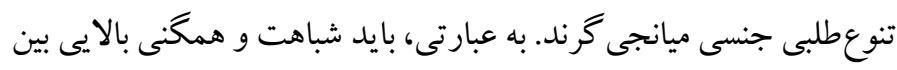
هيجانخواهى و طرحوارههاى شناختى دو نفر وجود داشته باشد تا بتوان

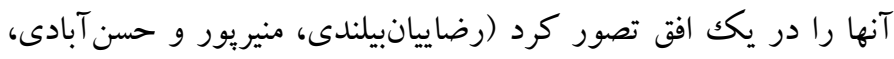

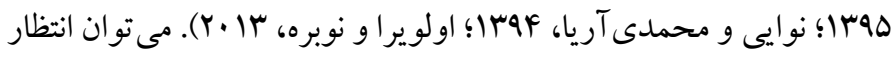
داشت افرادى كه در سطح شديد هيجانخواهى قرار دارند، تمايل دارند با محسى

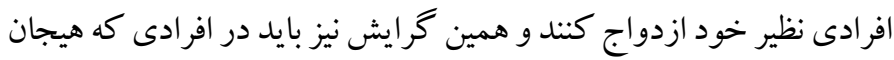

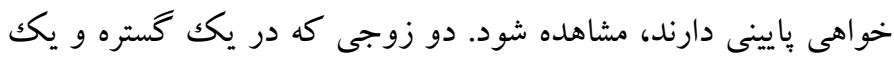

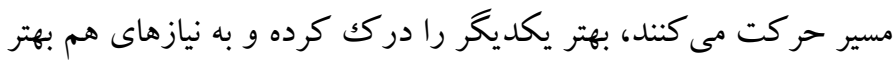

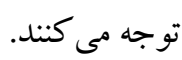
در اينجا بايد يادآور شد كه اين يثزوهش داراى محدوديتهايى است كه

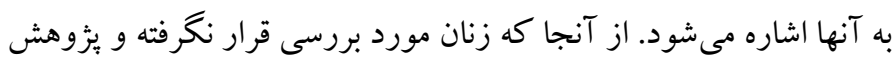

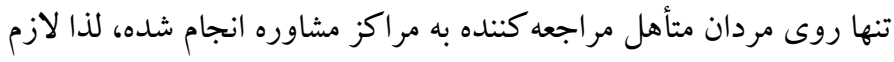

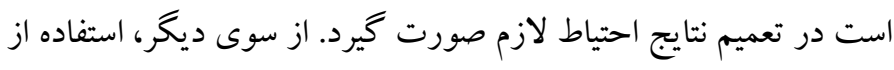

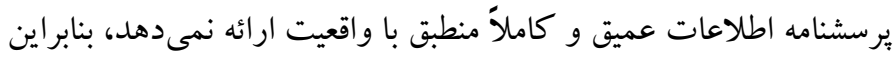
توصيه مى شود در يثزوهشهاى آتى از رويهاى تر كيبى استفاده شود. ضمن

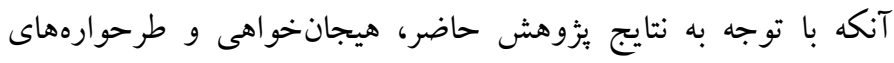
شناختى فعالشونده حدود rV درصد واريانس تنوع طلبى جنسى را تبيين مى تصى كنندكه نشان مىدهد عوامل ديخرى نيز بر تنوعطلبى جنسى تأثير دارند.

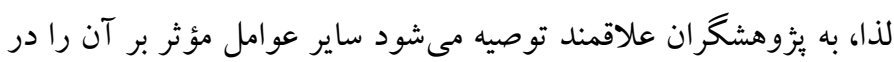




\section{References}

Alaghband, L., Sharifi, H. P., Farzad, V., \& Aghayousefi, A. (2020). Predicting emotional divorce based on emotional literacy, coping styles, quality of life, resilience mediation. Journal of Psychologicalscience, 19(90), 733-743. (Persian). [Link]

Alipour, F., Saeidpour, S., \& Hasani, J. (2015). The Comparison of Sensation Seeking in Sex Addicts, Stimulant Addicts, Opioid Addicts and Normal Individual. Journal of Mazandaran University of Medical Sciences, 25(125), 135-138. (Persian). [Link]

Andersen, B. L., \& Cyranowski, J. M. (1994). Women's sexual self-schema. Journal of personality and social psychology, 67(6), 1079-1100. Doi: 10.1037/0022-3514.67.6.1079. [Link]

Andersen, B. L., Cyranowski, J. M., \& Espindle, D. (1999). Men's sexual self-schema. Journal of personality and social psychology, 76(4), 645-661. Doi: 10.1037/0022-3514.76.4.645. [Link]

Arnett, J. (1994). Sensation seeking: A new conceptualization and a new scale. Personality and individual differences, 16(2), 289-296. Doi: 10.1016/0191-8869(94)90165-1. [Link]

Both, S., Laan, E., \& Schultz, W. W. (2010). Disorders in sexual desire and sexual arousal in women, a 2010 state of the art. Journal of Psychosomatic Obstetrics \& Gynecology, 31(4), 207-218. Doi: 10.3109/0167482X.2010.528628. [Link]

Cuntim, M., \& Nobre, P. (2011). The role of cognitive distraction on female orgasm. Sexologies, 20(4), 212-214. Doi: 10.1016/j.sexol.2011.08.001. [Link]

Desrichard, O., Vos, P., Bouvard, M., Dantzer, C., \& Paignon, A. (2008). The French version of the Arnett Inventory of Sensation Seeking: Internal and predictive validity. Personality and Individual Differences, $\quad 44(8), \quad$ 1673-1683. DOI:10.1016/j.paid.2008.01.020. [Link]

Efrati, Y., Shukron, O., \& Epstein, R. (2019). Compulsive sexual behavior and sexual offending: Differences in cognitive schemas, sensation seeking, and impulsivity. Journal of behavioral addictions, 8(3), 432-441. DOI: 10.1556/2006.8.2019.36. [Link]

Emadi, S., Mirhashemi, M., \& Pashasharifi, H. (2020). A structural model for prediction of couple burnout based on sensation seeking, perfectionism and emotion regulation strategies with the mediation of resiliency in married women. Journal of psychologicalscience, $\quad$ 19(92), 1011-1022. (Persian). [Link]

Frederick, D. A., Lever, J., Gillespie, B. J., \& Garcia, J. R. (2017). What keeps passion alive? Sexual satisfaction is associated with sexual communication, mood setting, sexual variety, oral sex, orgasm, and sex frequency in a national US study. The Journal of Sex Research, 54(2), 186-201. DOI: 10.1080/00224499.2015.1137854. [Link]

Glass, S. P., \& Wright, T. L. (1992). Justifications for extramarital relationships: The association between attitudes, behaviors, and gender. Journal of sex Research, 29(3), 361-387. Doi: 10.1080/00224499209551654. [Link]

Gomes, A. L. Q., \& Nobre, P. (2012). Early maladaptive schemas and sexual dysfunction in men. Archives of sexual behavior, 41(1), 311-320. DOI: 10.1007/s10508-011-9853-y. [Link]

John, N. A., Seme, A., Roro, M. A., \& Tsui, A. O. (2017). Understanding the meaning of marital relationship quality among couples in peri-urban Ethiopia. Culture, health \& sexuality, 19(2), 267-278. Doi: 10.1080/13691058.2016.1215526. [Link]

Mayzari Ali, R., Jangi, P., \& Sangani, A. (2019). Prediction of driving behavior based on emotion seeking and social control in public transport drivers suburban. Scientific Journal of Social Psychology, 7(51), 79-88. (Persian). [Link]

MacCallum, R. C., Browne, M. W., \& Sugawara, H. M. (1996). Power analysis and determination of sample size for covariance structure modeling. Psychological methods, 1(2), 130-149. Doi: 10.1037/1082-989X.1.2.130. [Link]

Medina, J. (2013). Causes that take to Infidelity: an analysis by sex. Acta De Investigacion Psicologica, 3(3), 1271-279. [Link]

Motahhary, Z. S., Behzadpoor, S., \& Sohrabi, F. (2013). Explanation of marital conflicts based on the sensation seeking and resilience in couples. Journal of woman \& study of family. 6(20), 105-122. (Persian). [Link]

Navaei, J., \& Mohammadi Arya, A. (2016). Association between the early maladaptive schemes and extra marital relationship among married people. Iranian Journal of Psychiatric Nursing, 3(4), 18-27. (Persian). [Link]

Nobre, P. J., \& Pinto-Gouveia, J. (2009). Questionnaire of cognitive schema activation in sexual context: A measure to assess cognitive schemas activated in unsuccessful sexual situations. Journal of Sex 
Research, 46(5), 425-437. DOI: 10.1080/00224490902792616. [Link]

Nobre, P. J., \& Pinto-Gouveia, J. (2006). Emotions during sexual activity: Differences between sexually functional and dysfunctional men and women. Archives of sexual behavior, 35(4), 491-499. DOI:10.1007/s10508-006-9047-1. [Link]

Otto, D. (2016). Gender and Sexual Diversity: A Question of Humanity. Melbourne Journal of International Law, 17(2): 477-488. [Link]

Oliveira, C., \& Nobre, P. J. (2013). Cognitive structures in women with sexual dysfunction: the role of early maladaptive schemas. The Journal of Sexual Medicine, 10(7), 1755-1763. Doi: 10.1111/j.17436109.2012.02737.x. [Link]

Paat, Y. F., Torres, L. R., Morales, D. X., Srinivasan, S. M., \& Sanchez, S. (2020). Sensation seeking and impulsivity as predictors of high-risk sexual behaviours among international travellers. Current Issues in Tourism, 23(21), 2716-2732. Doi: 10.1080/13683500.2019.1666808. [Link]

Peixoto, M. M., \& Nobre, P. (2015). Prevalence of sexual problems and associated distress among lesbian and heterosexual women. Journal of Sex \& Marital Therapy, 41(4), 427-439. Doi: 10.1080/0092623X.2014.918066. [Link]

Peixoto, M. M., \& Nobre, P. (2015). Cognitive schemas activated in sexual context: a comparative study with homosexual and heterosexual men and women, with and without sexual problems. Cognitive Therapy and Research, 39(3), 390-402. Doi: 10.1007/s10608-014-9661-5. [Link]

Peixoto, M. M., \& Nobre, P. (2017). "Macho" beliefs moderate the association between negative sexual episodes and activation of incompetence schemas in sexual context, in gay and heterosexual men. The Journal of Sexual Medicine, 14(4), 518-525. Doi: 10.1080/00224499.2018.1542656. [Link]

Peixoto, M. M., \& Nobre, P. J. (2020). Cognitiveemotional predictors of sexual functioning in lesbians, gays, and heterosexuals. Archives of Sexual Behavior, 49, 1823-1838. DOI: 10.1007/s10508-020-01732-9. [link]

Rezaeian Bilondi, H., Monirpour, N., \& Hasanabadi, H. R. (2016). Sexual variety seeking based on early maladaptive schemas, parenting styles and moods. Thoughts and Behavior in Clinical Psychology, 11(40), 7-16. (Persian). [Link]

Selterman, D., Garcia, J. R., \& Tsapelas, I. (2019). Motivations for extradyadic infidelity revisited. The
Journal of Sex Research, 56(3), 273-286. DOI: 10.1080/00224499.2017.1393494. [Link]

Sharifi, M., Haji Heidari, M., Khorvash, F., \& Fatehizadeh, M. (2013). Correlation between love schemas and justifications for extramarital involvement in married women. Journal of Research in Behavioural Sciences, 10(6), 526-534. (Persian). [Link]

Sharifian, M., Saffarinia, M., \& Alizadehfard, S. (2018). The role of gender schemas by mediating fairness style in predicting sexual pain disorder: Study of structural equation model. Journal of Health psychology,7(27):169-190. (Persian). [Link]

Wood, R., Hirst, J., Wilson, L., \& Burns-O'Connell, G. (2019). The pleasure imperative? Reflecting on sexual pleasure's inclusion in sex education and sexual health. Sex Education, 19(1), 1-14. Doi: 10.1080/14681811.2018.1468318. [Link]

Young, J. E., \& Brown, G. (2005). Young schema questionnaire-short form; Version 3. Psychological Assessment. Doi: 10.1037/t67023-000. [Link]

Ziyarati Kord, S. Z. (2020). Evaluating the difference between cognitive ability and emotion seeking in high risk and low risk individuals. Journal of psychologicalscience, 19(91), 893-903. (Persian). [Link]

Ziyayi, P., Sepehri Shamlou, Z., \& Mashhadi, A. (2013). The relationship between activating cognitive schemas, negative automatic thoughts and sexual arousal in married female college students. Journal of thought and behavior in clinical psychology, 8(28), 17-26. (Persian). [Link]

Zuckerman, M. (1971). Dimensions of sensation seeking. Journal of consulting and clinical psychology, 36(1), 45. Doi: 10.1037/h0030478. [Link] 